\title{
Die frühe Schenker-Rezeption Hellmut Federhofers
}

\author{
Thomas Wozonig
}

ABSTRACT: Der Aufsatz beschäftigt sich mit der frühen Schenker-Rezeption des österreichischen Musikwissenschaftlers Hellmut Federhofer (1911-2014), die in der Forschung bislang ebenso wenig Beachtung fand wie deren biographische und historische Voraussetzungen. Es zeigt sich, dass Federhofer, seit er während seiner Wiener Studienzeit mit wichtigen Persönlichkeiten aus dem Kreis um Heinrich Schenker in Kontakt gekommen war, dessen Arbeiten intensiv studierte und sich auch während der NS-Zeit mit ihnen auseinandersetzte. Dass er 1943 mit seiner Habilitationsschrift faktisch ein Schenker-Lehrbuch vorlegen konnte, lässt zudem darauf schließen, dass das Musikwissenschaftliche Institut der Karl-Franzens-Universität Graz, wenigstens aber dessen damaliger Leiter Werner Danckert, sich dieser Auseinandersetzung mit dem jüdischen Musiktheoretiker nicht widersetzte. Schon unmittelbar nach Kriegsende war Federhofer sowohl durch seine frühen Publikationen als auch durch seine Lehre an der Grazer Universität darum bemüht, Schenkers Lehren wieder in den musikwissenschaftlichen Fachdiskurs einzuführen, womit ihm mindestens innerhalb der deutschsprachigen Schenker-Rezeption eine Vorreiterrolle zukommt.

The present essay examines the early reception of Heinrich Schenker by the Austrian musicologist Hellmut Federhofer (1911-2014). The biographical and historical contexts of Federhofer's early publications on Schenker as well as their biographical and historical circumstances, have not yet been scrutinized. Since his first contact with the Schenker circle during his period of study in Vienna, Federhofer studied Schenker's works and continued to do so during the Nazi era. Since Federhofer's post-doctoral thesis (1943) is virtually a textbook on Schenkerian analysis, it seems likely that the department of musicology at the University of Graz, or at least Federhofer's supervisor Werner Danckert, tolerated the ideas of the Jewish theorist. This article examines Federhofer's earliest post-war publications and teaching activities to reveal his pioneering role in bringing Schenker to the surface of German-speaking musicological discourse.

Schlagworte/Keywords: biografische Forschung; biographical research; Geschichte der Musiktheorie; Graz; Hellmut Federhofer; history of music theory; Karl-Franzens-Universität; reception of Heinrich Schenker; Schenker-Rezeption

Hellmut Federhofer (1911-2014) gehört in mehrfacher Hinsicht zu den bedeutendsten und bemerkenswertesten Persönlichkeiten der deutschsprachigen Nachkriegsmusikwissenschaft. So ist es allein schon bemerkenswert, dass sich eine wissenschaftliche Karriere überhaupt über den Zeitraum eines Dreivierteljahrhunderts erstreckt: Im Falle Federhofers wird diese Spanne durch seine Dissertation Akkordik und Harmonik in frühen Motetten der Trienter Kodices (1936) ${ }^{1}$ und einen 2013 entstandenen Beitrag über Richard Wagner, dessen Veröffentlichung sein Autor nicht mehr erlebte, abgesteckt. ${ }^{2}$ Einen Grundpfeiler seines umfangreichen Schaffens stellt die Auseinandersetzung mit der Musik des Mittelalters, der Renaissance, des Barock und der Wiener Klassik dar. Den größten Einsatz widmete er dabei den theoretischen Arbeiten Christoph Bernhards und Johann Joseph Fux'

1 Federhofer verfasste 30 Jahre später auch einen entsprechenden Artikel für die erste Ausgabe der Musik in Geschichte und Gegenwart (Federhofer 1966).

2

Federhofer 2015. 
(von 1955 bis 2006, mit einer Unterbrechung von 1967 bis 1987 leitete er die FuxGesamtausgabe), während andererseits, aus einer südösterreichischen Perspektive gesehen, seine Regionalforschungen zur Musikgeschichte der Steiermark und Kärntens mindestens ebenso bedeutsam waren. ${ }^{3}$ Diesem breiten Feld stand ab seiner Berufung an die Universität Mainz im Jahr 1962 die Auseinandersetzung mit neuer Musik gegenüber, deren Entwicklung der 1911 Geborene - damit in jenem Jahr, in dem der von ihm häufig attackierte Arnold Schönberg seine Harmonielehre, aber auch seine Gurre-Lieder vollendete - unmittelbar erlebte und verfolgte. Federhofers Verhältnis zur neuen Musik war dabei bekanntermaßen ein problematisches: Zeitlebens stand er ihr äußerst kritisch bis ablehnend gegenüber, wobei der wesentliche, über Jahrzehnte hinweg unverändert erhobene Vorwurf an die neue Musik auf den Bruch mit vormals gültigen, von Federhofer als ınatürlich` empfundenen (Hör-)Konventionen zielte. Vor allem mit der Preisgabe der DurMoll-Tonalität habe sich die neue Musik in einer Weise gegen den größten Teil des Publikums gestellt, die sie nicht nur ästhetisch, sondern letztlich gesellschaftlich problematisch mache: Sie erlaube nur einer Handvoll Spezialisten die Auseinandersetzung mit ihr und stehe folglich »nicht nur quer zu den musikalischen Interessen der Gesellschaft, sondern auch zu den Grundprinzipien einer auf Volkssouveränität beruhenden Gesellschaftsordnung, in der es keine Privilegien bevorzugter Schichten, einzelner Gruppen und Persönlichkeiten geben sollte. « ${ }^{4}$ Für Aufsehen und Irritationen sorgte aber vor allem seine Überzeugung, die spsychologische` wie ıästhetische` Unterlegenheit der neuen Musik empirisch belegen und ihre `Unnatürlichkeit` durch Hörstudien aufzeigen zu können. Hierbei spielte der Musikpsychologe Albert Wellek (1904-1972), den Federhofer nach gemeinsamer Studienzeit in Wien an der Universität Mainz wiedertraf, eine zentrale Rolle: Neben seinen Verdiensten auf dem Gebiet der Musikpsychologie ist Wellek vor allem durch seine verächtliche Haltung gegenüber neuer Musik im Gedächtnis geblieben, wie er sie in seinem berüchtigten Artikel »Atonalität« in der ersten Auflage der Musik in Geschichte und Gegenwart darlegte. ${ }^{5}$ Die empirischen Studien Federhofers und Welleks führten nach ihren Publikationen bekanntlich zu einer heftigen Auseinandersetzung mit Carl Dahlhaus, in die sich weitere Wissenschaftler einschalteten. ${ }^{6}$

Dabei wurde bereits mehrfach darauf hingewiesen ${ }^{7}$, dass sich zentrale Aspekte der Ansichten Federhofers nicht zufällig mit den wesentlichen Prinzipien eines anderen Musiktheoretikers deckten, den er intensiv studierte und für dessen Rezeption er sich sein

Vgl. Suppan 2009.

4 Federhofer 2000/2002, 436.

5 Vgl. Laaff/Wellek 1951. In dem gemeinsam mit Ernst Laar verfassten Artikel - jener lieferte die erste, wesentlich sachlichere Hälfte - bezeichnet er »Atonale Musik« - wenig überraschend wird der Begriff weder ernsthaft reflektiert noch sinnvoll differenziert - als eine »psychologisch wie ästh. völlig undurchführbare[], illusorische[] Konstruktion auf dem Papiere, die einer seelen- und wirklichkeitsfremden Schreibtischperspektive entstammt. [...] Atonalität [...] ist kein Programm, sondern das Gegenteil eines solchen: es ist ein rein negatives und dabei tyrannisches Programm, das in seinen Folgen alles, gerade auch alle Freiheit der Erfindung ertötet.« Der »vollständige Schiffbruch der atonalen Bewegung», den jene bereits nach kurzer Zeit erlitten habe, sei demnach unvermeidbar gewesen ob der »Unnatur «, auf welcher dieser »Versuch« beruhe (ebd., 763f.).

6 Der Disput wurde durch Dahlhaus 1971 (»Ist die Zwölftontechnik sillusorisch»? Eine Erwiderung «) als Reaktion auf Federhofer/Wellek 1971 (»Tonale und dodekaphonische Musik im experimentellen Vergleich«) losgetreten und durch Welleks Tod 1972 beendet. Vgl. Suppan 2002, 5; Gruber 2013. 
Leben lang einsetzte: Heinrich Schenker. Dessen Theorien hatte Federhofer noch während seiner Studienzeit in Wien durch den Kontakt zum Schenker-Kreis kennengelernt, und seine 1943 verfasste Habilitationsschrift bezeugt eine intensive Auseinandersetzung mit dessen Arbeiten, die während der NS-Zeit als Werke eines jüdischen Autors offiziell aus dem musikwissenschaftlichen und musiktheoretischen Diskurs verbannt waren. Auch Federhofers erste, kurz nach Kriegsende publizierten Texte sind Schenker gewidmet. In Verbindung mit seiner Lehr- und Betreuungstätigkeit am Musikwissenschaftlichen Institut der Karl-Franzens-Universität Graz wurde Federhofer so zu einem Vorreiter der österreichischen Nachkriegsrezeption Schenkers - ein Umstand, der, wie deren Voraussetzungen, in der Forschung bisher kaum bekannt war.

Der vorliegende Aufsatz behandelt daher diesen biographischen Knotenpunkt der 1930er und 1940er Jahre: Zunächst werden Federhofers in Graz begonnene und in Wien fortgesetzte musikalische Ausbildung sowie seine an der Universität Wien betriebenen musikwissenschaftlichen Studien durchleuchtet. ${ }^{8}$ Das Gros der folgenden Ausführungen entfällt dann auf Federhofers Auseinandersetzung mit Heinrich Schenker, die sich, Mitte der 1930er Jahre durch Kontakt zum engsten Schenker-Kreis ausgelöst und maßgeblich angeleitet, nach seiner Rückkehr nach Graz intensivierte und sich erstmals in seiner 1943 vorgelegten Habilitationsschrift manifestierte.

\section{FEDERHOFERS KÜNSTLERISCHE UND WISSENSCHAFTLICHE AUSBILDUNG ${ }^{9}$}

Insgesamt ergibt sich aus den vorhandenen Quellen in Bezug auf Federhofers Zeit in Wien das Bild eines jungen Musikers, der offenbar längere Zeit eher mit einer Laufbahn als Komponist oder ausübender Musiker liebäugelte denn mit einer wissenschaftlichen Karriere. Dem »zukünftige[n] Musik-Doktor « ${ }^{10}$ scheinen die historischen Vorlesungen zu jener Zeit offenbar noch wenig zugesagt zu haben, während praktische und kompositorische Aktivitäten im Vordergrund standen.

Ersten Klavier- und Theorieunterricht erhielt Hellmut Federhofer zwischen 1926 und 1930 in Graz von dem Pianisten Anatol Graf Vietinghoff-Scheel, der vor allem durch die Konstruktion seines $>$ Chromatophons Bekanntheit erlangte ${ }^{11}$, und dem Musiktheoretiker

8 An dieser Stelle möchte ich mich sehr herzlich bei Hellmut Federhofers Tochter, Marie-Theres Federhofer, Professorin für deutsche Literaturwissenschaft und Kulturstudien an der Universität Tromsø, bedanken, die mir Fotokopien von Briefen und Postkarten aus dem Nachlass ihres 2014 verstorbenen Vaters zukommen ließ, die sich für die Aufarbeitung der hier behandelten Zusammenhänge als sehr ergiebig erwiesen.

9 Biographische Informationen zu Hellmut Federhofer sind in diversen Musiklexika (u.a. Eggebrecht 2001, Federhofer 2016, Hilscher 2001, Suppan 2009) und den ihm gewidmeten Festschriften (etwa Riedel/Unverricht 1971, Mahling 1988) leicht verfügbar, weswegen auf sie im Folgenden nicht im Detail verwiesen wird. Lediglich in der Literatur voneinander abweichende Angaben werden gesondert gekennzeichnet.

10 So Alban Berg in einem Brief an Guido Adler vom 23. Februar 1934 (Fotokopie im Besitz des Autors). Diesen Text druckte Federhofer später - sicher nicht zuletzt aufgrund Bergs lobender Worte ihm gegenüber - auch in einer Fußnote seines Aufsatzes »Meine Erinnerungen an Alban Berg« ab (Federhofer 1982/2002, 97).

11 Bei diesem Instrument war ein Lichtapparat mit einer Klaviatur gekoppelt (vgl. László 2006 [1939], 308). Federhofer erwähnt die Erfindung einmal beiläufig in einem Brief an Alban Berg vom 8. Dezember 1933 (Fotokopie im Besitz des Autors). 
und Komponisten Leopold Suchsland. Vietinghoff-Scheel dürfte Federhofer nicht nur die fundierte Klaviertechnik zu verdanken haben, die ihn zu einem durchaus virtuosen Pianisten und Cembalisten machte ${ }^{12}$, sondern überhaupt einen ersten umfassenden Zugang zur Musik, der Federhofer nach eigenen Worten »dazu bestimmte, an eine musikalische Laufbahn zu denken « ${ }^{13}$. Durch Vermittlung Suchslands kam Federhofer 1931 für weiteren Unterricht in »Harmonielehre, Kontrapunkt, Formenlehre und Komposition ${ }^{14} \mathrm{zu}$ dem Komponisten, Musiktheoretiker und Fuchs-Schüler Richard Franz Stöhr (1874-1967). ${ }^{15}$ Nach eigenen Angaben absolvierte Federhofer $1934^{16}$ auch die Kapellmeisterklasse Oswald Kabastas (1896-1946) an der Wiener Musikakademie ${ }^{17}$ und erhielt zudem Klavierunterricht beim damals bereits über siebzigjährigen Emil von Sauer, mit dem er bis zu dessen Tod im April 1942 in gutem und regelmäßigem Kontakt stand. ${ }^{18}$ Abgerundet wird dieses Spektrum musikalischer Tätigkeiten durch seine Korrepetitionsdienste für die von Heinz Schulbaur geleitete Opernklasse an der Musikakademie. ${ }^{19}$

Im Zuge dieser umfassenden, für den Beginn des 20. Jahrhunderts allerdings nicht ungewöhnlichen künstlerischen Ausbildung nahm Federhofer in den Jahren 1933/34 privaten Kompositionsunterricht bei Alban Berg. Diesem Unterricht widmete er 1982 einen kurzen Aufsatz, in welchem er nicht nur Einblicke in seine frühen Ausbildungsjahre und seine Studienzeit gibt, sondern auch offenbart, wie stark sein damaliges Denken über die musikalische Moderne von seiner erst später eingenommenen ablehnenden Haltung abwich. Ganz offen spricht er davon, „daß ich mich in meinen Jugendjahren der Dodekaphonie nicht verschloß, sondern ihr Sympathie entgegenbrachte. Erst später bezog ich unter Einfluß von Heinrich Schenkers Lehre - kritische Stellungnahme zu ihr. "Schon durch den Klavierunterricht bei Vietinghoff-Scheel sei er »neben dem klassischen Repertoire« auch mit damals modernen Komponisten in Kontakt gekommen; »[f]ür Neue Musik

12 Nach dem Zeugnis Albert Welleks $(1971,9)$ besaß Federhofer eine besondere Affinität zum Werk Frédéric Chopins, was sich später auch in einigen Aufsätzen niederschlug. Auch Josef-Horst Lederer berichtet in seinem Nachruf (Lederer 2014), dass Federhofer noch mit 90 Jahren, anlässlich der Verleihung des Ehrendoktorats in der Aula der Karl-Franzens-Universität Graz, Chopins Revolutionsetüde op. 10/12 öffentlich vortrug.

13 Federhofer 1982/2002, 94.

14 Ebd., 95.

15 Vgl. Heller 2017.

16 Vgl. Federhofer 2001. In vielen, mitunter noch zu Lebzeiten Federhofers veröffentlichten Biographien findet sich die Jahresangabe 1936, so in Eggebrecht 2001.

17 Über den Unterricht bei Kabasta äußerte sich Federhofer ausführlich im Brief an Alban Berg vom 8. Dezember 1933 (siehe oben, Anm. 11). Mit Ausnahme einer Teilnahme an einem Sommerkurs des Salzburger Mozarteums sind keine weiteren dirigentischen Ambitionen Federhofers belegt (vgl. die Salzburger Chronik für Stadt und Land 72/198 [29. August 1936], 10, sowie das Salzburger Volksblatt 66/1, ebenfalls vom 29. August 1936, 7-8).

18 Für Federhofers Zeit in Wien ist lediglich ein öffentlicher Auftritt als Pianist im Oktober 1941 im Brahms-Saal des Musikvereins belegt. Wie ein Brief von Sauers (22. Dezember 1941, Fotokopie im Besitz des Autors) nahelegt, scheint Federhofer, entgegen dem Urteil seines Lehrers, mit dem Konzert nicht zufrieden gewesen zu sein, obgleich sich auch ein knapper Zeitungsbeitrag wohlwollend über den Abend äußerte (vgl. Skorzeny/Daumer/Tenschert 1941).

19 Vgl. den Brief von Federhofer an Alban Berg vom 8. Dezember 1933 (siehe oben, Anm. 11). Eine Reihe von Fotografien, die sich in den Beständen der Österreichischen Nationalbibliothek erhalten haben, geben einen Einblick in das bunte, vor allem dem deutschen Singspiel gewidmete Repertoire, das in Schulbaurs Klasse behandelt wurde. 
dadurch aufnahmebereit ${ }^{20}$, vertiefte er sein Interesse an den damaligen fortschrittlichen Strömungen durch das Studium von Schönbergs Harmonielehre sowie der Reihen Anbruch und 23 - Eine Wiener Musikzeitschrift, die von Willi Reich herausgegeben und unter anderem von Theodor W. Adorno mit einzelnen Beiträge beliefert wurde - beide bekanntermaßen ebenfalls Schüler Alban Bergs. Federhofers rege Auseinandersetzung mit der damaligen musikalischen Moderne, die sich im letzten, später nicht veröffentlichen Kapitel seiner Habilitationsschrift ${ }^{21}$ in profunder Repertoirekenntnis äußert, mündete auch in einer Handvoll Kompositionen, die er zuerst dem an der Wiener Universität lehrenden Egon Wellesz und später Alban Berg vorlegte. ${ }^{22}$ Die zu dieser Zeit erfolgte $>$ Machtergreifung ‘ der Nationalsozialisten stellte besonders für Letzteren eine gravierende, existenzbedrohende Zäsur dar. Willi Reich berichtete über diese für Berg schwerste Zeit: »Unablässig sann er über Mittel nach, mit denen er seine Einkünfte hätte erhöhen können. Vor allem aber steigerte er sein Arbeitstempo immer mehr und mehr [...]. Von diesem Augenblick an waren ihm nur noch wenige kurze Zeiten der Entspannung und Erholung gegönnt. « ${ }^{23}$ Dementsprechend willkommen dürfte ihm ein zusätzlicher, zudem so motivierter Schüler wie Federhofer gewesen sein.

Die Daten der erhaltenen Korrespondenz zwischen Federhofer und Berg lassen darauf schließen, dass der Unterricht im Laufe der zweiten Jahreshälfte 1933 begann. Interessanterweise, so berichtete Federhofer später, wurde er von Berg auf Basis seiner traditionelleren, noch unter Stöhrs Anleitung entstandenen Werke akzeptiert, während ihn seine »atonalen Stücke [...] offenbar weniger oder gar nicht zu beeindrucken schienen « ${ }^{24}$. Unglücklicherweise hat sich aus dem Unterricht bei Berg offenbar keine Komposition erhalten. ${ }^{25}$ Überhaupt scheint Federhofer sich später von seinen Ausbildungsjahren, die nicht zuletzt von einer intensiven Beschäftigung mit neuer Musik geprägt waren, distanziert zu haben:

Ich war selbst ein wenig neugierig, ob sich noch Kompositionen meines Vaters erhalten haben, als ich seinen Briefnachlass mit nach Tromsø nahm. Aber ich habe leider nichts gefunden [...]. Er hat auch nie darüber gesprochen (ich habe allerdings auch nie gefragt), und manchmal scheint es mir, als habe er diese Periode in seinem Musiker-/Musikwissenschaftler-Leben irgendwie gelöscht. ${ }^{26}$

Berg fungierte auch als Vermittler zu Guido Adler, bei dem er für Federhofer um Einsicht in die Trienter Codices anfragte. ${ }^{27}$ Über diese legte Federhofer 1936 seine Dissertation mit dem Titel Akkordik und Harmonik in frühen Motetten der Trienter Codices vor, womit er sein Studium der Musikwissenschaft an der Universität abschloss. Wenige Jahre bevor Federhofer sich inskribierte, hatte das Musikwissenschaftliche Institut der Universität Wien einen großen Umbruch erfahren: 1927 war Guido Adler, erster Ordinarius für

20 Federhofer 1982/2002, 94.

21 Federhofer 1943, 115-128.

22 Vgl. Federhofer 1982/2002, $96 f$.

23 Reich 1963, 83.

24 Federhofer 1982/2002, 96.

25 Im Brief an Berg vom 8. Dezember 1933 (siehe oben, Anm. 11) werden »17.Variationen [...] mit einem etwas ausgedehnteren Finale« erwähnt, die er auch zu orchestrieren plante.

26 E-Mail von Marie-Theres Federhofer an den Autor vom 3. November 2017.

27 Vgl. Briefkarte Alban Bergs an Guido Adler vom 23. Februar 1934 (Fotokopie im Besitz des Autors). 
Musikwissenschaft im deutschen Sprachraum, nach fast 30 Jahren emeritiert. Entgegen seinem Anraten - neben einer Reihe eigener Schüler hatte er auch den in Bern tätigen Ernst Kurth vorgeschlagen - wurde der bekennende Antisemit Robert Lach ${ }^{28}$ (1874-1958) zum Nachfolger bestimmt, der aufgrund seiner Gesinnung mehrmals mit der moderaten, sich »antijüdischen Aktionen [...] widersetzen[den] « ${ }^{29}$ Haltung der geisteswissenschaftlichen Fakultät in Konflikt geraten sollte (so versuchte er - vergeblich - die Berufung Egon Wellesz' zum außerordentlichen Professor zu verhindern). ${ }^{30}$ Auch verließen nach Adlers Emeritierung dessen Schüler Wilhelm Fischer und Rudolf von Ficker, den man kurzzeitig von 1928 bis 1931 zurück ans Institut geholt hatte, die Universität. 1932 wurde der Lehrkörper um den gerade erst habilitierten Leopold Nowak ergänzt. Wie Michael Staudinger aufzeigt $^{31}$, verlagerte sich die inhaltliche Ausrichtung des Instituts nach Adlers Abgang von dessen stilkundlichen Interessen zunehmend auf die Regional- und Lokalforschung ein Schwerpunkt, den Federhofer später, auf entsprechende institutionelle Grundlagen gestützt, in Graz weiterführen sollte. Nach dem >Anschluss` und der Ablöse Lachs durch Erich Schenk 1939 blieben die Lehrinhalte Nowaks sowie der ebenfalls am Institut lehrenden Alfred Orel und Robert Haas ihren Titeln nach zwar unauffällig, in ihren Publikationen aber tritt der Einfluss der nationalsozialistischen Ideologie deutlich zutage.

Dies gilt in besonderem Maße für Federhofers Doktorvater Alfred Orel (1889-1967), zu dem Federhofer möglicherweise schon vor seiner Tätigkeit an der Universität in Verbindung gestanden haben könnte. Orel war (gemeinsam mit Hans Gál ${ }^{32}$ ) an einer neuen Auflage der Formenlehre der Musik von Federhofers früherem Lehrer Richard Franz Stöhr beteiligt, für die er eine umfangreiche Einleitung über »Das Werden der musikalischen Formen « beisteuerte. ${ }^{33}$ Wohl in der Mitte der 1930er Jahre entwickelte Orel Sympathien für den Nationalsozialismus: Er berichtete seit Mitte 1937 im »Amtlichen Organ der NSKulturgemeinde« Die Musik über das Wiener Musikleben, wurde später Mitglied der NSDAP und ließ in Publikationen seine starke Neigung zum Gedankengut des Nationalsozialismus an den Tag treten, welche seine Schriften zu Mozart ebenso durchziehen wie

Robert Lach war seit den frühen 1920er Jahren von Wien aus beratend in den Prozess um die Einrichtung eines musikwissenschaftlichen Lehrstuhls in Graz involviert gewesen, wobei seine Gesinnung an der Grazer Universität auf stärkeren Widerhall stieß als in Wien. So konnte er 1925 den als Kandidaten für den Lehrstuhl gehandelten Paul Nettl ganz ungeniert als »Volljude von reinstem Schlage« diffamieren, während er den von ihm favorisierten Robert Haas als einen »durch und durch stramm deutsch und arisch fühlende[n] « Mann bezeichnete, für den gerade das »kernarische und kerndeutsche Graz [...] der richtige Boden wäre. "Tatsächlich ließ diese deutsch-nationale und antijüdische Stimmung in Graz auch Guido Adler einsehen, dass der von ihm ins Spiel gebrachte Egon Wellesz für »die reichsdeutschen Brüder« in Graz undenkbar war, da jene nur Leute ihrer eigenen Gesinnung »anbringen« wollten (vgl. Flotzinger 1990, 18-26; Zitate: 23).

29 Potter 2000, 134.

30 Vgl. ebd.

31 Vgl. Staudinger 2006, 242-245.

32 Mit Gál (1890-1987) stand Federhofer seit Ende der 1960er Jahre nachweislich in brieflichem Kontakt. Unter anderem lieferte Gál in seinen Schreiben, die von Spott und Verachtung gegenüber neuer Musik durchsetzt sind, entscheidende Anregungen für einige von Federhofer durchgeführte Hörversuche; vgl. den von Günter Wagner herausgegebenen, von Seiten des zur Zeit der Veröffentlichung noch lebenden Federhofer allerdings unvollständigen Briefwechsel (»)Der Teufel selbst kann nicht merken, was echt und was falsch ist««, Wagner 1996). 
seine Studien zur Musik des Mittelalters. ${ }^{34}$ Während diese Denkweise aber ebenso ohne jeden (affirmativen) Einfluss auf Federhofer blieb wie Orels Beschäftigung mit Bruckner (die zu jener Zeit allerdings einem allgemeinen Schwerpunkt des Instituts entsprach und während der NS-Zeit zusätzlichen Auftrieb erhielt), hat Orels Interesse an mehrstimmiger Musik des Spätmittelalters tiefere Spuren in Federhofers wissenschaftlichem Profil hinterlassen. Seine Dissertation hatte Orel ebenfalls über die Trienter Codices verfasst ${ }^{35}$, seine Habilitation wiederum Über rhythmische Qualität in mehrstimmigen Tonsätzen des 15. Jahrhunderts ${ }^{36}$. Inwieweit vielleicht Orels Skepsis gegenüber neuer Musik wie auch seine späteren, überraschenden Sympathien für Grundgedanken der Musiktheorie Heinrich Schenkers Einfluss auf Federhofer hatten, ist trotz auffälliger Parallelen schwer zu beurteilen. ${ }^{37}$ Jedenfalls blieb die Verbindung Federhofers zu Orel zeitlebens offenbar eine enge, und er widmete seinem Doktorvater, der nach dem Krieg aufgrund seiner Aktivitäten und Beziehungen während der NS-Zeit keine akademische Anstellung mehr erhielt, sowohl eine Festschrift ${ }^{38}$ als auch einen Nachruf. ${ }^{39}$

\section{FEDERHOFER UND DER SCHENKER-KREIS}

Federhofers Studienzeit in Wien fiel in eine für die Schenker-Produktion und -Rezeption bedeutsame Phase. Bekanntlich starb Schenker am 13. Januar 1935 und damit während der Studienzeit Federhofers. In diesem Jahr erschien auch posthum Schenkers musiktheoretisches Hauptwerk Der freie Satz, das am Ende einer sich über Jahrzehnte erstreckenden

34 So überträgt Orel zentrale Elemente der NS-Ideologie auf die Zeit Mozarts: »Daß in der verhältnismäßig kurzen Zeit von kaum drei Geschlechterfolgen ein derartiger Sieg errungen werden konnte, wie ihn die Lage der deutschen Musik etwa beim Tode Beethovens zeigt, dies beweist nicht nur die Größe der Führer in diesem Streite, sondern ebensosehr die Intensität, mit der er geführt wurde, wie die Kraft, die unser Volkstum auszustrahlen imstande war. Denn worum ging es letztlich in diesem ganzen Zeitraum? Galt es nicht, die Befreiung der süddeutschen Kunst von jahrhundertelanger Überfremdung und den Aufbau einer neuen, aus echtem deutschem Geist erwachsenden, unlöslich im eigenen Volkhaften verwurzelten Kunst? - Denn nicht darauf kommt es an, ob man im einzelnen gegenständliche Zusammenhänge mit der Volksmusik feststellen kann, sondern ob die neue Kunst ihre geistige Nahrung aus dem heimatlichen Boden, aus dem eigenvölkischen Wesen empfängt, ob der Künstler bewußt als Angehöriger seines Volkes, gewissermaßen bewußt unterschieden vom fremdvölkischen, dadurch aber auch schon in einem gewissen Gegensatz zu diesem, seinen Weg geht. (Orel 1941, 14)

35 Orel 1977 [1919].

36 Orel 1922.

37 In seinem Aufsatz »Die Wende zur `Neuen Musik» im historischen Aspekt« (Orel 1954) benennt Orel ein »bewußtes Zerreißen« der »innige[n] Vereinigung von Mensch (im angedeuteten Sinn) und Kunstwerk « als »Wesensgrundzug « der neuen Musik: »Der Mensch wird aus seiner zentralen Stellung in der Kunst und im Kunstwerk verdrängt« (ebd., 5), wobei dieser Befund »im Technischen durch die Verdrängung der dominantischen Spannung, damit aber auch des Fundamentalbasses, der architektonischen Kadenzgrundlage, des ganzen Raumes der Tonalität aus ihrer zentralen Stellung gekennzeichnet« sei (ebd., 7). Der Bezug auf Schenkers Konzepte andererseits wird an mehreren Stellen angedeutet wie etwa der Betonung der sarchitektonischen Kadenzgrundlage «: "Eine Bachsche Fuge, wie ein Beethovenscher Sinfoniesatz [...] stellen wortwörtlich eine ins Riesenhafte erweiterte Kadenz dar« (ebd., 6). Bezeichnenderweise dient für diese Stellen nicht Schenker, sondern dessen prominenter Fürsprecher Wilhelm Furtwängler (vor allem dessen Gespräche über Musik, Zürich 1948) als Referenz (so auch für das zuletzt angeführte Zitat).

38 Federhofer 1960

39 Federhofer 1967. 
Entwicklung und Präzisierung seiner theoretischen Vorstellungen steht. Schon in Schenkers 1895 in mehreren Teilen erschienenem Aufsatz »Der Geist der musikalischen Technik ${ }^{40}$ sind einige wesentliche Gedanken ausgeprägt, die in späteren Schriften wie der Harmonielehre (1906), der Monographie zu Beethovens Neunter Symphonie (1912) und dem Kontrapunkt (1910 und 1922), vor allem aber den Reihen Der Tonwille (1921-24) und Das Meisterwerk in der Musik (1925-30) weitergeführt werden. Daneben waren Schenkers kommentierte Notenausgaben weit verbreitet. ${ }^{41}$ Zu Schenkers Lebzeiten verhalfen ihm seine Schriften allerdings nur zu begrenztem Erfolg: Obgleich man bereits wenige Jahre nach der Jahrhundertwende in Kommentaren und Rezensionen auf seine Schriften zu reagieren begann und seine Theorien populärer waren, als es lange Zeit (auch von Schenker selbst) behauptet wurde, erreichten sie insgesamt doch nur einen eher kleinen Kreis an Theoretiker*innen, Privatschüler*innen und Interessent*innen. Wohlhabende unter ihnen finanzierten teilweise die Veröffentlichung seiner Schriften, während er seinen Lebensunterhalt vor allem als Klavier- und Theorielehrer verdiente (die praktische Musikausübung nahm bekanntlich eine Schlüsselfunktion in seinem Denken ein); ${ }^{42}$ eine Anstellung an einer angesehenen Musikinstitution blieb ihm zeitlebens verwehrt.

Nur wenige Monate nach Schenkers Tod wurde am Neuen Wiener Konservatorium von seinen Schülern Moriz Violin (1879-1956), Oswald Jonas (1897-1978) und Felix Salzer (1904-1986) das Schenker-Institut gegründet (1935-38), »das es sich zur Aufgabe gestellt hat, Musikern, Musikinteressierten, Instrumentalisten, Dirigenten Musiktheorie nun nicht als ein in sich begrenztes Spezialfach, sondern als eine alle Musikdisziplinen umfassende und sich in ihnen auswirkende Lehre zu vermitteln « ${ }^{43}$; darüber hinaus gaben Jonas und Salzer seit 1937 die (allerdings bereits im Folgejahr wieder eingestellte) Zeitschrift Der Dreiklang heraus, die auf die Person und das Wirken Schenkers ausgerichtet war. ${ }^{44}$ Jenseits der österreichischen Grenzen waren ähnliche Unternehmungen bereits einige Jahre zuvor umgesetzt worden: Nach der Anstellung Reinhard Oppels am Leipziger Konservatorium (1927) war 1930-34 am Stern'schen Konservatorium in Berlin mit Oswald Jonas ein zweiter Schenker-Schüler an einer bedeutenden deutschen Bildungseinrichtung tätig. Dazwischen hatten Moriz Violin und, auf ausdrückliche Empfehlung Schenkers, Felix-Eberhard von Cube in Hamburg ein Schenker-Institut als Privatschule gegründet. ${ }^{45}$ Alle diese Unternehmungen mussten unter dem Druck der seit 1933 regierenden Nationalsozialisten freilich bald wieder eingestellt werden. Da nicht nur derartige Aktivitäten unterbunden, sondern vor allem wichtige Personen aus dem Umfeld Schenkers zur Emigration getrieben wurden, entwickelte die Schenker-Rezeption vor allem in den Vereinigten Staaten enorme Zugkraft; ${ }^{46}$ hier ist neben Jonas, Salzer und Violin auch

40 Schenker 1895.

41 Vgl. Cook 2007, 272.

42 Seine ausdrücklich der musikalischen Interpretation gewidmete, zu Lebzeiten unveröffentlichte Schrift Die Kunst des Vortrags wurde der Wissenschaft erst 2000 in einer Übersetzung von Irene Schreier Scott bekannt (Schenker 2000).

43 Bamberger 1936, 8. Carl Bamberger (1902-1987) hatte 1920-24 bei Schenker Musiktheorie und Klavier, daneben bei Friedrich Buxbaum Cello studiert.

44 Vgl. Cook 2007, 273.

45 Vgl. Drabkin 2002, 835; Drabkin 1986, $187 f$.

46 Vgl. Drabkin 2002, 835. 
der Jonas-Schüler Ernst Oster ${ }^{47}$ zu nennen. Hans Weisse (1892-1940), ein weiterer Schenker-Schüler und Lehrer Alvin Baumanns, welcher später wiederum der Lehrer von Allen Forte werden sollte, hatte Deutschland dagegen bereits einige Zeit vor der >Machtergreifung verlassen. ${ }^{48}$

Über seinen Kontakt zum Schenker-Kreis informiert Federhofer nur knapp in seinem Essay Meine Erinnerungen an Alban Berg. Demzufolge geht die Verbindung auf einen Kollegen in der Dirigierklasse Kabastas zurück, nämlich Manfred Willfort, der möglicherweise bereits seit 1927 Unterricht beim oben erwähnten Weisse erhalten hatte. Erst nach dessen Emigration nach New York Ende 1931 stieß Willfort schließlich zu Schenker und gehörte für einige Jahre zu dessen engen Mitarbeitern, eher er Anfang 1934 - unter anderem wegen Arbeitsverzugs und seines Studiums bei Kabasta - in Ungnade fiel. ${ }^{49}$ Möglicherweise kommt Kabastas Unterricht als gemeinsamer Ausbildungsrahmen für Willfort und Federhofer, aber auch Salzer (siehe unten) sogar eine noch grundsätzlichere Bedeutung zu, denn mehrfach wurde Kabasta große Sympathie für Schenkers Arbeiten nachgesagt (ein ausführlicherer Kontakt zwischen den beiden lässt sich allerdings nicht belegen). ${ }^{50}$ Näher geht Federhofer auf seine Kontakte jener Zeit nicht ein, allerdings lassen sich mögliche Verbindungslinien zu den Protagonisten der Wiener SchenkerRezeption Felix Salzer, Oswald Jonas und Moriz Violin aufzeigen. Die Verbindungen zu Violin, der lange Jahre in Deutschland als Pianist tätig gewesen und erst 1933 nach Wien zurückgekehrt war, dürften wohl von der gemeinsamen Lehrtätigkeit Violins mit Salzer und Jonas am Wiener Schenker-Institut herrühren. Das Verhältnis zu Violin war offenbar ein gutes, da sich Federhofer nach Kriegsende beim in die Vereinigten Staaten ausgewanderten Richard Stöhr nach dem ebenfalls emigrierten Violin erkundigte. ${ }^{51}$ Auch mit dem sieben Jahre älteren Salzer hatte Federhofer sicher im Rahmen des Schenker-Instituts zu tun; möglicherweise kamen die beiden aber, wie oben erwähnt, bereits früher in Kontakt, denn wie Federhofer besuchte auch Salzer die Dirigierklasse bei Kabasta (Abschluss 1935).$^{52}$ In Bezug auf Federhofers späteres Wirken ist vor allem Salzers Bestreben hervorzuheben, Schenkers Theorien auch auf mittelalterliche Musik zu übertragen. ${ }^{53} \mathrm{Am}$ näch-

Vgl. Schenker Documents Online, http://www.schenkerdocumentsonline.org/profiles/person/entity000649.html (30.6.2018).

Vgl. Slottow 2008, 262; Schenker Documents Online, http://www.schenkerdocumentsonline.org/profiles/ person/entity-000951.html (30.6.2018).

49 Vgl. Federhofer 1982/2002, 99; zur Biographie Manfed Willforts vgl. Schenker Documents Online, http://www.schenkerdocumentsonline.org/profiles/person/entity-000964.html (30.6.2018). Über die späteren Spannungen geben einige der Tagebucheinträge Schenkers Aufschluss, so etwa jene vom 23. März, 6. April, 22. April, 25. Mai, 21. Juni und 6. September 1934; vgl. Schenker Documents Online, http://www.schenkerdocumentsonline.org/profiles/person/entity-000964.html (30.6.2018).

50 Vgl. Schenker Documents Online, http://www.schenkerdocumentsonline.org/profiles/person/entity003836.html (30.6.2018)

51 Vgl. hierzu einen Brief Stöhrs an Federhofer vom 22. April 1948 (Fotokopie im Besitz des Autors).

52 Vgl. Harten 2001.

53 Siehe auch unten, Anm. 87. Im Vorwort seiner 1935 erschienen Monographie Sinn und Wesen der abendländischen Mehrstimmigkeit benennt Salzer Schenkers Lehre als »das Fundament der gesamten musikalischen Betrachtungsweise« seiner Untersuchungen (Salzer 1935, 5). Das behandelte Repertoire reicht dabei von Beispielen der frühesten abendländischen Mehrstimmigkeit (Werke etwa der St.Martial-Schule und der Notre-Dame-Schule) bis in den Frühbarock, streift aber auch die Musik Johann Sebastian Bachs. Sein 1952 erschienenes Hauptwerk Structural Hearing (Salzer 1952), das auf dieser 
sten stand Federhofer aber wohl Oswald Jonas, mit dem ihn eine lebenslange Freundschaft verband. Mit Jonas, obgleich dieser erst nach Beendigung seiner Lehrtätigkeit am Stern'schen Konservatorium in Berlin 1934 nach Wien zurückgekehrt war, dürfte Federhofer die Analyse nach Schenker gelernt bzw. vertieft haben: In einer Fußnote seiner Beiträge zur musikalischen Gestaltanalyse (1950) erwähnt er, dass er »die Skizzen zu diesen und den folgenden Analysen [...] während meiner Studienzeit unter Anleitung meines verehrten Lehrers Herrn Dr. Oswald Jonas in den Jahren 1936-37 entworfen [habe] « ${ }^{54}$. Eine andere, nicht weniger prominente Figur des Schenker-Kreises, mit der Federhofer in engem Kontakt stand, war Anthony van Hoboken (1887-1983), mit dem er sich auch später rege über die Theorien Schenkers austauschte. ${ }^{55}$

In der zweiten Hälfte der 1930er Jahre wurde Schenker so allmählich zum zentralen Bezugspunkt für Federhofers musikalisches Denken, wie sich an mehreren Parallelen in ihren ästhetischen Ansichten und theoretischen Konzepten zeigt: ${ }^{56}$ so in der gemeinsamen Überzeugung, dass die Dur-Moll-Tonalität auf Basis eines unumstößlichen Konsonanz-Dissonanz-Gegensatzes das wichtigste Prinzip der abendländischen Musik darstelle, ${ }^{57}$ in der Auffassung, dass diese Musik auf ein 'Grundgerüst` und letztlich einen 'Ursatzı, der sich in der Horizontale und in mehreren Schichten entfalte, zurückgeführt werden könne; darin dass dieses Prinzip seinen vollendeten Ausdruck in den 'genialen Meisterwerken ‘ der deutsch-österreichischen Musikgeschichte zwischen Bach und Brahms finde und neue Musik demgegenüber eine Verfallserscheinung darstelle; ${ }^{58}$ schließlich in der Ablehnung einer selbstgenügsamen, spekulativen Musiktheorie, die nicht unmittelbar den gültigen >Meisterwerken ‘ entstammt und sich folglich von einer zu bevorzugenden sdeskriptiven ${ }^{59}$ Musiktheorie unterscheide. ${ }^{60} \mathrm{Im}$ künstlerisch-wissenschaftlichen Selbstverständnis ist Schenker wie Federhofer die Bedeutung gemeinsam, die sie der praktischen

Arbeit basiert, dehnt den behandelten Zeitraum bis zu damaligen Zeitgenossen Salzers wie Ralph VaughanWilliams, Igor Strawinsky oder Aaron Copland aus.

54 Federhofer 1950, 39, Anm. 1.

55 Dem Autor liegen zwei Schreiben van Hobokens an Federhofer vom 5. September 1956 und vom 28. November 1956 als Fotokopien aus dem Nachlass Federhofers vor.

56 Umgekehrt muss aber klar festgehalten werden, dass Federhofer viele der Ansichten Schenkers ablehnte, im Grundsätzlichen beispielsweise den glühenden Nationalismus (Michael Mann sprach einmal davon, dass einige der Äußerungen Schenkers »in style and spirit, could well have come from the pen of the Führer himself«; Mann 1949, 9), im Speziellen etwa die Verehrung für Beethoven, die von Federhofer nur bedingt geteilt wurde (oder sich zumindest nur marginal in seinen Schriften niederschlug).

57 »Mehr Gesetze als Konsonanz und Dissonanz gibt es nicht, auch nicht mehr Grundableitungen. Man muß sogar die Dissonanz als bloß durch die Konsonanz bedingt auffassen und somit die Konsonanz der Natur allein als aller tonkünstlerischer Möglichkeiten urletzten Grund, wie zugleich als letztes Ziel alles Durchgängig-Strebenden erkennen« (Schenker 1922b, 3).

58 Dementsprechend stellen Federhofers Hörtests, die er gemeinsam mit Albert Wellek durchführte (siehe oben), noch eine Übersteigerung der Überzeugung Schenkers dar, die Qualität von Musik an das Vorhandensein für ihn maßgeblicher musiktheoretischer Prinzipien knüpfen zu können (vgl. etwa Schenkers Polemik in Schenker 1926, vor allem 190f.). Gelegentlich setzte aber auch Federhofer Analysen nach Schenker den »neuen, als zukunftsträchtig proklamierten Ton- und Klangsysteme[n] sowie d[en] aleatorischen und akustischen Experimente[n] « der neuen Musik gegenüber, um deren "gesellschaftliche Belanglosigkeit« analytisch zu begründen (vgl. Federhofer 1997/2002, Zitate: 301).

59 Dieser Begriff wird mehrfach von Federhofer in Bezug auf Schenkers Musiktheorie verwendet, vgl. etwa Federhofer 1947/2013, 2, Anm. 2, und Federhofer 1950, 79.

60 Allem Bekenntnis zum Trotz finden sich auch bei Schenker gelegentlich Momente spekulativen Denkens, etwa in seiner Intervalllehre am Beginn der Harmonielehre (vgl. Schenker 1906, 37-39). 
Musikausübung beimessen. ${ }^{61}$ Schließlich wird in Federhofers Denken beständig der Glaube an die Allgemeingültigkeit der Theorien Schenkers offenbar, wie sie, nicht ohne selbstverherrlichende Tendenz, auch von jenem selbst proklamiert worden war. Eine geradezu prophetische Verklärung des Meisters war auch unter Schenkers Schülern allgegenwärtig, die sich als die »wahren, nach Wahrhaftigkeit Ringenden « verstanden, »die es unablässig trieb, nach dem Wesenskern des genial-musikalischen Schaffens zu forschen ${ }^{62}$. Wolfgang Suppan schließt auch Federhofer in diese Gruppe mit ein, wenn er schreibt, dass »[a]lle, die als Schüler oder Enkelschüler die Ideen eines Mannes aufgenommen und weitergetragen haben, der den Königsweg in das Herz der Musik ebenso wie die Wunder organischer Bildung der großen Meisterwerke (Viktor Zuckerkandl) zu offenbaren wußte, [haben] lebenslang mit großer Konsequenz an Schenkers Grundsätzen festgehalten [haben]. $\star^{63}$

\section{FEDERHOFER UND GRAZ}

Nach seinem Weggang aus Wien erhielt Federhofer 1937 eine Anstellung als Bibliothekar an der Technischen Hochschule Graz, an welcher sein Vater als Professor beschäftigt war. Diese Anstellung behielt er bis zu seiner Ernennung zum außerordentlichen Professor an der Karl-Franzens-Universität Graz 1959, in deren Folge er für seine bis hierhin ehrenamtliche Leitung des musikwissenschaftlichen Instituts erstmals ein regelmäßiges Gehalt bezog. ${ }^{64}$ In Graz setzte Federhofer seine musikwissenschaftlichen Studien und Forschungen fort, wobei seine spätere Wirkungsstätte, das Institut für Musikwissenschaft der Karl-Franzens-Universität, bei seiner Rückkehr 1937 noch gar nicht existierte. Erst im Herbst 1940 berief man Herbert Birtner (1900-1942), gebürtiger Hamburger und seit 1938 außerordentlicher Professor an der Universität Marburg ${ }^{65}$, nach Graz und beauftragte ihn (auch hier als außerordentlicher Professor) mit der Gründung und Leitung des Instituts. Unter Birtner wurden in Graz die wesentlichen Strukturen geschaffen und inhaltliche Pfade eingeschlagen, welche das Institut auf lange Sicht prägen sollten, so etwa die ersten Schritte für eine Gesamtausgabe der Werke Johann Josef Fux' oder die Einrichtung einer 'Landschaftsstelle für Musikı, die auf Birtners Vortrag "Die landschaftlichen Aufgaben der Musikwissenschaft in der Steiermark « zurückging. ${ }^{66}$ Durch die im Sommer 1941 unter Mitwirkung des Reichsgaues gegründete `Landschaftsstelle`, die möglicherweise bereits auf älteren Strukturen fußte ${ }^{67}$, sollte $» d a s$ neue Institut zu einem Zentrum der musikhisto-

61 Auch als Lehrender vertrat Federhofer später die Auffassung, dass »ein Studium der Musikwissenschaft nur bei gleichzeitiger musikpraktischer Ausbildung, die an der Universität nicht stattfindet, sinnvoll ist. « (Federhofer 1964b, 75)

62 Bamberger 1936, 7.

63 Suppan 2002, 5 (Hervorhebungen original).

$64 \mathrm{Vgl}$. Flotzinger 1990, 68.

65 Vgl. Blume 1999.

66 Vgl. ebd.

67 Schon Ernst Fritz Schmid, der lediglich im Wintersemester 1934/35 und Sommersemester 1935 in Graz wirkte, scheint entsprechende Quellenstudien betrieben zu haben (konkret zu Handschriften aus dem Stift St. Lambrecht), die möglicherweise in Verbindung mit seiner Lehre standen. Schon davor finden sich Hinweise auf entsprechende Pläne, die in den frühen 1930er Jahren zwischen Robert Lach und 
rischen Forschung für Steiermark, Kärnten und die angrenzenden Gebiete gestaltet werden ${ }^{68}$. Diese Einrichtung, die bis mindestens 1947 und damit noch unter Federhofers Leitung betrieben wurde, entfaltete eine intensive Sammeltätigkeit, die gerade für Federhofers eigene Studien zur Regionalforschung einen bedeutenden Quellenfundus bereitstellte.

Nach Birtners Tod an der Ostfront 1942 blieb dessen Stelle, trotz Bemühungen um einen Nachfolger, bis Kriegsende vakant. Allerdings wurde 1943 der damals in Berlin tätige Werner Danckert (1900-1970) als Vertretung nach Graz beordert, wo er bis zum Ende des Wintersemesters 1944/45 tätig war. ${ }^{69}$ Die Bestellung dürfte mit Blick auf die von der Volksliedforschung bestimmte Ausrichtung des Instituts ganz bewusst erfolgt sein, galt Danckert, der eine Ausbildung als Konzertpianist und später ein Studium der Musikwissenschaft in Erlangen und Leipzig (Promotion 1924) absolviert hatte, doch schon in seinen Dreißigern als einer der führenden Volksliedforscher in Deutschland. Prominent in Erscheinung getreten war er während der großen, (offiziell) ersten größeren musikwissenschaftlichen Tagung der NS-Zeit, die unter dem Leitthema »Musik und Rasse« während der Reichsmusiktage in Düsseldorf im Mai 1938 stattfand (und damit im selben Rahmen wie die berüchtigte Ausstellung »Entartete Musik«). Hier hielt Danckert während der letzten Sitzung einen Vortrag mit dem Titel »Volkstum, Stammesart, Rasse im Lichte der Volksliedforschung". Auch wenn es sich bei diesem überdeutlich titulierten Referat nach Einschätzung Pamela Potters wohl eher um » ein[en] zahme[n] Versuch, die Volksmusikstile unterschiedlicher deutscher Volksgruppen miteinander zu vergleichen, ohne jemals auf die >Rasse « Bezug zu nehmen ${ }^{70}$ handelte, und obgleich ihn auch sein weiteres Schaffen rein äußerlich nicht als glühenden Anhänger der nationalsozialistischen Ideologie ausweist $^{71}$, war er dem nationalsozialistischen Kulturapparat doch eng verbunden: $\mathrm{Er}$ zählte zu den wesentlichen Beratern im Amt Rosenberg, wo er - neben anderen prominenten Wissenschaftlern wie Erich Schenk, Karl Gustav Fellerer, Georg Schünemann, Rudolf Gerber oder Werner Korte - für Herbert Gerigks Abteilung Musik arbeitete. Nicht zuletzt deswegen konnte er nach 1945 seine akademische Laufbahn nicht fortsetzen. ${ }^{72}$

Als Federhofer 1937 in Graz eintraf, existierte vor Ort zwar noch kein musikwissenschaftliches Institut, doch gab es seit Jahren ein zumindest elementares Angebot an musikwissenschaftlichen und -theoretischen Vorlesungen, für die seit dem Wintersemester 1935/36 vor allem Victor von Urbantschitsch (1903-1958) verantwortlich war (der Österreich allerdings nach dem >Anschluss` verlassen musste). ${ }^{73}$ Inwieweit Federhofer Urbantschitsch und damit möglicherweise auch dessen zweimal angebotene Lehrveranstaltung "Strömungen und Probleme zeitgenössischer Musik an Hand praktischer Übungen« noch

dem Germanisten Karl Polheim (1883-1967; 1939-45 Rektor der Universität Graz) bestanden (vgl. Flotzinger 1990, 31-33).

Aus einem Brief der Kommission zur Wiederbesetzung der Lehrkanzel für Musikwissenschaft an den Dekan der Geisteswissenschaftlichen Fakultät vom 5. November 1942, zitiert nach ebd., 53.

70 Potter 2000, 232.

71 Eine vollständige Liste seiner Publikationen findet sich in Suppan 1971, 95-99.

72 Vgl. ebd., 94.

73 Vgl. Flotzinger 1990, 33-37. 
selbst erlebte, ist nach aktueller Quellenlage unklar. ${ }^{74}$ Nach Urbantschitschs Weggang wurde seine Stelle von dem Komponisten und Dirigenten Franz Mixa (1902-1994) nachbesetzt, dessen musikhistorische Vorlesungen klar auf die Musik Beethovens fokussiert waren. ${ }^{75}$ Daneben umfasste Mixas Lehrangebot einige Grundlagenkurse zur Musiktheorie, die für den umfassend ausgebildeten Federhofer wohl kaum mehr interessant gewesen sein dürften. Erst mit der Übernahme Birtners ab dem Wintersemester 1940/41 florierte am neugegründeten Institut ein Forschungs- und Lehrbetrieb, der mit mehreren Kursen aus dem Bereich der `Alten Musikı und der Wiener Klassik ${ }^{76}$ stärker der späteren Ausrichtung Federhofers entsprach und diese womöglich entscheidend mit beeinflusste. ${ }^{77}$

Nach dem Ende des Zweiten Weltkriegs übernahm Federhofer schließlich ehrenamtlich die Leitung des Instituts, das nach dem Weggang Danckerts im Februar 1945 und mangels weiteren wissenschaftlichen Personals zu Kriegsende praktisch aufgehört hatte zu existieren. Obgleich nach wie vor in einem Dienstverhältnis zur Technischen Hochschule Graz stehend, gewährleistete er bereits ab dem Wintersemester 1945 wieder einen durchgehenden Lehrbetrieb. Ähnlich wie in der kurzen Amtszeit Birtners weist auch Federhofers Lehrangebot ${ }^{78}$ einen deutlichen Schwerpunkt auf der Musikgeschichte des 16. bis 18. Jahrhunderts auf und schließt zudem auch die Musik des Mittelalters ein. Die Wiener Klassik ist neben unspezifischen Titeln (etwa Wintersemester 1946/47 »Die Instrumentalmusik des 18. Jhs. «; Wintersemester 1954/55 „Grundlagen der musikalischen Klassik«) ausschließlich mit Bezug auf Wolfgang Amadeus Mozart vertreten ${ }^{79}$, während es über die Jahre verstreut immerhin fünf Kurse zur musikalischen Romantik gibt - bezeich-

74 Aufgrund der seit Januar 2018 geltenden Datenschutzregelungen war es dem Verfasser nicht möglich, die im Archiv der Karl-Franzens-Universität Graz vorhandenen Inskriptionslisten für den betreffenden Zeitraum einzusehen.

75 Wintersemester 1938/39 sowie Sommersemester 1939: jeweils »Formstudien an Hand der Beethovenschen Violinsonaten«; Wintersemester 1941/42: "Formanalyse der Klaviersonaten Beethovens« (vgl. Flotzinger 1990, 37, Anm. 128).

76 Sommersemester 1941: „Heinrich Schütz und seine Zeit«, „Übungen zur Musikgeschichte des 17. Jhs.», »Einführung in die Notenschriftkunde«; Wintersemester 1941/42: „Einführung in die Instrumentenkunde und Aufführungspraxis alte Musik», "Zur Musikgeschichte des 18. Jahrhunderts«; Sommersemester 1942: „Übungen zur Musikgeschichte des 18. Jahrhunderts«, „Übungen zur Geschichte der Notenschrift (Tabulaturkunde) (vgl. ebd., 49, Anm. 166).

77 Es ist unklar, ob Birtner, immerhin seit 1936 Vorsitzender der Neuen Schütz-Gesellschaft, Impulse zu Federhofer 1950/2013 (»Der strenge und freie Satz und sein Verhältnis zur Kompositionslehre von Heinrich Schütz in der Fassung seines Schülers Christoph Bernhard«) geliefert hat.

78 Dem Verzeichnis fehlen die Lehrveranstaltungen vom Sommersemester 1948 und Wintersemester 1948/49. Da auch der zeitgleich am Institut lehrende Joseph Marx hier keine Kurse anbot, muss eine grundsätzliche Aussetzung des Lehrbetriebs angenommen werden. Es irritiert daher, dass Flotzinger kurz zuvor vom »lückenlosen Lehrangebot ab WS 45/46« spricht (1990, 63). Ein Fehler in seiner Aufzählung ist daher nicht ausgeschlossen (vgl. ebd., 62f. und 66).

79 Allerdings erscheint die erste Lehrveranstaltung mit Mozart-Bezug erst im Wintersemester 1955/56 (»W.A. Mozart und seine Zeit«), von da an aber in jedem der drei folgenden Semester. Gleichzeitig hat Federhofer (von einer Analyse in seiner Habilitationsschrift abgesehen; siehe unten, Federhofers frühe Arbeiten zu Heinrich Schenker: Musikalische Form als Ganzheit) 1957 das erste Mal, von da an aber regelmäßig, zu Mozart publiziert, sodass hier klar eine Verbindung zwischen Forschung und Lehre hergestellt werden kann. 
nenderweise die späteste behandelte Epoche. ${ }^{80}$ Damit steckt Federhofer in seiner (freilich sich über einen längeren Zeitraum erstreckenden) musikhistorischen Lehre einen weiteren zeitlichen Rahmen als seine Vorgänger ab. Von wesentlich größerem Interesse sind allerdings die von Federhofer geleiteten musiktheoretischen Kurse, insbesondere zu »Kontrapunkt", die er vom Wintersemester 1945/46 bis zum Wintersemester 1947/48, nochmals vom Sommersemester 1955 bis zum Sommersemester 1956 sowie ein letztes Mal im Sommersemester 1961 anbot. Ihm zur Seite stand seit dem Sommersemester 1947 (und bis zum Sommersemester 1957) der gebürtige Grazer Joseph Marx (1882-1964).

Unter den hier behandelten Gesichtspunkten ist Marx' Anwesenheit in Graz vor allem deswegen bedeutsam, da er in Wien mit Heinrich Schenker in Kontakt gestanden und dessen Arbeiten mit regem Interesse verfolgt hatte; so hatte Marx geplant, ein Schulbuch auf Basis von Schenkers Harmonielehre für seinen Unterricht an der Musikakademie zu verfassen, ein Vorhaben allerdings, das er nie umsetzte. Im Neuen Wiener Journal, für welches Marx 1931-38 als Musikkritiker tätig war, veröffentlichte er 1935 einen schwärmerischen Nachruf auf Schenker, der sich bruchlos in den Stil des Schenker-Kreises fügt. ${ }^{81}$ Dementsprechend dürfte am Grazer Institut der späten 1940er und 1950er Jahre ein für Schenkers Theorien offenes Klima geherrscht haben. Innerhalb des gemeinsam gestalteten Lehrbetriebs deckte Marx, bis auf eine Ausnahme ${ }^{82}$, vor allem die Fächer Harmonie- und Formenlehre ab, während Federhofer die Kontrapunkt-Kurse oblagen. Diese Aufteilung erscheint für einen überzeugten Anhänger Schenkers durchaus nachvollziehbar, gehören doch die "grundlegenden, an jeder akkordisch-harmonisch fundierten Musik beobachtbaren Stimmführungserscheinungen « nach Schenkers Theorien und Federhofers entsprechender Überzeugung »ausschließlich der Kontrapunktlehre an ${ }^{83}$ damit verbunden war eine dem gesamten Schenker-Kreis eigene Skepsis gegenüber der "schulmäßigen Harmonie- und Formenlehre ${ }^{84}$. Wesentlich bedeutsamer sind allerdings die (obgleich nur dreimal angebotenen ${ }^{85}$ ) Kurse mit dem Titel „Gestaltanalytische Übungen «. In diesen Seminaren, deren Titel auf den von Federhofer immer wieder betonten Zusammenhang zwischen Schenkers Lehren und der Gestalttheorie hinweist ${ }^{86}$, wurden, wie etwa Wolfgang Suppan ${ }^{87}$ und Gernot Gruber $^{88}$ bezeugen, tatsächlich die Theorien

Im Wintersemester 1960/61 sowie im Sommersemester 1961 bot Federhofer »Die Musik im Zeitalter der Romantik« an; ebenfalls 1961 hielt er ein Referat über »Die Diminution in Klavierwerken von Chopin und Liszt« (veröffentlicht als Federhofer 1963).

81 Marx 1935. Der Text wurde bereits zwei Jahre nach Kriegsende wiederveröffentlicht in Ortner 1947, 405-408.

82 »Wesen des Kontrapunkts« im Sommersemester 1956, das sicher nicht zufällig in jenes Jahr fällt, in dem auch Federhofer nach längerer Zeit wieder Kontrapunkt-Kurse anbot (vgl. Flotzinger 1990, 66, Anm. 218).

83 So Federhofers Formulierung in Federhofer 1950, 62.

84 Diese setzt Federhofer in seinem Aufsatz "Die Musiktheorie Heinrich Schenkers« (Federhofer 1947/2013, 1) den Konzepten Schenkers gegenüber. Schon den ersten jemals im Dreiklang veröffentlichten Aufsatz hatte Felix Salzer mit dieser allgegenwärtigen Kritik an der »heute an den meisten Schulen gebräuchliche[n] Harmonie- und Kompositionslehre« eröffnet (Salzer 1937, 3).

85 Sommersemester 1947, Wintersemester 1956/57, Sommersemester 1957.

86 Siehe unten, Abschnitt Federhofers frühe Arbeiten zu Heinrich Schenker: Musikalische Form als Ganzheit.

87 Vgl. Suppan 1997, 471.

88 Im persönlichen Gespräch mit dem Autor im Januar 2018. Nach Grubers Erinnerungen sei Federhofer in seiner Lehre den Methoden und Begrifflichkeiten Schenkers allerdings nicht derart stark verhaftet gewe- 
Schenkers behandelt, womit Federhofers Lehre zumindest in Österreich eine Vorreiterrolle zukommt: Erst seit den frühen 1950er Jahren und damit einige Jahre nach Federhofers erster Abhaltung der `Gestaltanalytischen Übungen` war Schenker durch den Unterricht Franz Eibners dann auch an der damaligen Wiener Musikhochschule präsent; 1974 wurde Schenkers Lehre in Form eines Lehrstuhls »Tonsatz nach Heinrich Schenker « mit Eibner als erstem Ordinarius, 1976 schließlich mit einem eigenen Lehrgang an der Institution verankert. ${ }^{89}$ Daneben ist nicht auszuschließen, dass auch in anderen Kursen am Grazer Institut, etwa jenen zur Musik der Renaissance und des Barock, nach Schenker gearbeitet wurde, denn schließlich betont Federhofer bereits in seinen frühesten Schriften, dass es sich bei wesentlichen Prinzipien Schenkers »um grundsätzlich überall dort wiederkehrende Erscheinungen handelt, wo ein musikalischer Verlauf akkordisch-harmonisch fundiert ist ${ }^{90}$. Die Bedeutung der Lehren Schenkers für den Grazer Institutsbetrieb wird schließlich dadurch untermauert, dass unter Federhofers Leitung die bereits vor 1945 nicht unwesentlichen Literaturbestände zu Schenker ${ }^{91}$ beinahe bis zur Vollständigkeit ergänzt wurden. ${ }^{92}$

Dass Federhofer im Hinblick auf Schenkers Theorien nachhaltigen Einfluss auf einige seiner Studierenden ausgeübt hat, lässt sich anhand mehrerer Beispiele belegen. Hierzu zählen allerdings, etwas überraschend, gerade nicht die am Institut verfassten Abschlussarbeiten: Tatsächlich hat sich während Federhofers Zeit am Institut nur eine Dissertation explizit mit Schenkers Theorien auseinandergesetzt, nämlich Friedrich Neumanns Der Typus des Stufenganges der Mozart'schen Sonatendurchführung, die 1958 vorgelegt wurde. Der aus Salzburg gebürtige Neumann (1915-1989) hatte nach einer umfassenden künstlerischen Ausbildung - unter anderem ein 1941 am Mozarteum abgeschlossenes Kompositionsstudium sowie Dirigierunterricht bei Clemens Krauss und Hermann Abendroth - schon seit 1945 einen Lehrauftrag am Mozarteum inne, ehe er für seine Promotion nach Graz kam. Da er zudem bereits durch musiktheoretische Schriften in Erscheinung getreten war ${ }^{93}$, ist denkbar, dass er sich dezidiert an Federhofer wandte, um Schenker zu studieren bzw. bereits zuvor erworbene Kenntnisse in eine Doktorarbeit einfließen zu lassen. Seine Arbeit stellt jedenfalls eine der ersten, wenn nicht die erste deutschsprachige

sen, wie es seine frühen Schriften nahelegen. Vielmehr sei es Federhofer um das übergeordnete Prinzip des (freilich auch für Schenker wesentlichen) Konsonanz-Dissonanz-Gegensatzes und seiner Entfaltung gegangen, dem er bis in die Musik des Mittelalters nachging.

89 Eibner (1914-1986) hatte wie Federhofer in den 1930er Jahren bei Richard Stöhr und Oswald Jonas sowie ferner bei Anton Webern studiert (vgl. Schwab-Felisch 2005a, 369; Cook 2007, 275; Universität für Musik und darstellende Kunst Wien [o.J.], http://www.mdw.ac.at/schenkerlehrgang/franz_eibner.html [30.6.2018]).

90 Federhofer 1950/2013, 15.

91 Siehe unten, Abschnitt Federhofers frühe Arbeiten zu Heinrich Schenker: Musikalische Form als Ganzheit.

92 Zwischen 1945 und 1961 wurden die Monographie zur Fünften Sinfonie Beethovens (Schenker 1922a; erworben 1946), Ein Beitrag zur Ornamentik (1908; erworben 1955), alle drei Bände von Das Meisterwerk in der Musik (1925, 1926 und 1930; erworben: 1956), Der Freie Satz (1956; erworben 1957) sowie die von Jonas herausgegebene und von Elisabeth Mann-Borgese übersetzte Harmonielehre (Schenker 1954; erworben 1955) angeschafft.

93 Neumann 1951; Neumann 1955. 
Dissertation der Nachkriegszeit zu Heinrich Schenker dar. ${ }^{94}$ Ein wesentlich bekannteres Beispiel für einen Studenten, der durch Federhofer mit den Theorien Schenkers in Kontakt kam, ist der früh verstorbene Harald Kaufmann, mit dem sich Federhofer später allerdings überwarf. ${ }^{95}$ Kaufmann (1927-1970) hatte 1948 neben seinem Philosophiestudium sein musikwissenschaftliches Rigorosum absolviert und veröffentlichte später zwei Aufsätze, in denen er sich kritisch mit Schenkers Konzepten und ihrem geistesgeschichtlichen Hintergrund auseinandersetzte und die Analysemethode auf die Musik Max Regers anwandte. ${ }^{96}$ Einen anders gearteten Einfluss hatte Federhofer wiederum auf Wolfgang Suppan: Sowohl bei Federhofer promoviert (1959) als auch (in Mainz) habilitiert (1971), publizierte Suppan seit den 1960er Jahren Beiträge, in denen er die Schichtenlehre auf die Volksliedforschung übertrug. ${ }^{97}$

\section{FEDERHOFERS FrÜHE ARBEITEN ZU HEINRICH SCHENKER: MUSIKALISCHE FORM ALS GANZHEIT}

In den Mittelpunkt seiner Habilitationsschrift stellt Federhofer die Frage, wodurch sich musikalische Form in der Wahrnehmung konstituiert und wie man sich ihr in der Analyse am besten nähern könnte. Er geht dabei von dem der Psychologie entlehnten Phänomen der 'Gestaltqualitätı aus, wie es ein halbes Jahrhundert zuvor Christian von Ehrenfels, wiederum in Reaktion auf Ernst Machs Beiträge zur Analyse der Empfindungen (Jena 1886), in seinem bedeutenden Essay Über Gestaltqualitäten in die Musikwissenschaft eingeführt hatte. ${ }^{98}$ Ehrenfels' Gedanken, die sich allerdings lediglich auf kürzere melodische Tonfolgen bezogen hatten und die erst Erich von Hornbostel 1930 auf weitere Aspekte des musikalischen Satzes übertrug ${ }^{99}$, lieferten wichtige Impulse für die Musiktheorie: Einige Theoretiker begannen, die Prinzipien der Gestalttheorie auf neue Konzepte formaler Verläufe zu übertragen und hierdurch in deutliche Opposition zum damals

94 Drabkin $(1986,182)$ spricht dieses Verdienst Karl-Otto Plum und seiner 1979 in Regensburg vorgelegten Dissertation Untersuchung zu Heinrich Schenkers Stimmführungsanalyse zu, die freilich, anders als Neumanns Arbeit, bereits im Titel auf Schenker verweist.

95 1963/64 lieferten sich beide im Zusammenhang mit einer Festschrift anlässlich der Erhebung des damaligen Grazer Landeskonservatoriums zur Akademie für Musik und darstellende Kunst eine höchst kontroverse Auseinandersetzung, die mit Federhofers kritischem Essay »Gegen eine Schmähung der deutschsprachigen Musikwissenschaft« (Federhofer 1964a) angestoßen wurde. Zielscheiben Federhofers waren neben Kaufmann (»Ich gestehe, daß mir das Bekenntnis schwer fällt, Kaufmann zu meinen einstigen Schülern zählen zu müssen«; ebd., 218) ferner die Akademie und ihre Festschrift als Ganzes. Diverse Dokumente zu dieser Auseinandersetzung, die letztlich sogar zur Ergreifung rechtlicher Schritte von Seiten der Akademie unter ihrem damaligen Direktor Erich Marckhl führte, sind im Archiv der Kunstuniversität Graz erhalten (Signatur: UA KUG/AK/AV_021).

96 Kaufmann 1969a (»Fortschritt und Reaktion in der Analyselehre Heinrich Schenkers«) und 1969b (»Aushöhlung der Tonalität bei Reger«).

97 Vgl. Suppan 1997, 471. Hier (Anm. 1) gibt Suppan auch einen Überblick über seine entsprechenden Publikationen.

98 Nach Ehrenfels sind auch andere Sinnesorgane zur Wahrnehmung von Gestaltqualitäten befähigt, etwa in der Flächen- oder der »Raumvorstellung« (1890, 259-262; Zitat: 260).

99 "So ist das Musikstück eine Gestalt. Auch die herausanalysierten Momente sind Gestalten: so die melodische Wendung, der Rhythmus, die Form; die Folgen der Tonintervalle, der Zeitintervalle, der Sätze, Strophen, Zeilen, Themen; die Tonintervalle, Zeitintervalle, Themen selbst.« (Hornbostel 1930, 13) 
allgegenwärtigen, vor allem durch Hugo Riemann geprägten Formdenken zu treten. Diese Entwicklungen sind vor dem Hintergrund einer seit Jahrzehnten gewachsenen Spannung zu verstehen, die aus dem Gegensatz zweier divergierender Konzepte von `Form tierte: Das Denken in »räumlich-architektonisch akzentuierte[n] musikalische[n] Formschemata " auf der einen, die Annahme eines »den musikalisch-zeitlichen Prozess betonenden Organismusmodells « auf der anderen Seite, wie sie nicht zuletzt in den Theorien Riemanns und Schenkers in einem bisweilen paradoxen Nebeneinander begegnen. ${ }^{100}$ Ohne dass es jemals zur Ausprägung einer einheitlichen Bewegung oder Traditionslinie gekommen wäre, können der kleinen Gruppe von Anhängern der Gestalttheorie im deutschsprachigen Raum vor allem Ernst Kurth, Hans Mersmann, Kurt Westphal, Herman Reichenbach, Erich Doflein und (in einigem zeitlichen Abstand) Ernst Toch zugerechnet werden. ${ }^{101}$

Der für Federhofer wesentliche Bezugspunkt dieser Gruppe ist Kurt Westphal. Dieser prägte den Begriff der /Verlaufskurve`, welche er als wesentliche Eigenschaft musikalischer Form begriff: »Die Verlaufskurve hält die Teile zusammen, bestimmt die Funktion, die sie für das Ganze zu erfüllen haben, setzt die Teile zueinander in Beziehung und gibt ihnen im Hinblick auf das höhere Ganze, dem sie angehören, einen Sinn. « ${ }^{102}$ Wesentlich an Westphals Konzept ist die »Funktion der Reproduktion von Musik als ein[] für das Verständnis von Form wesentliche[r] Aspekt. Die höhere Formebene ist also nicht einfach gegeben, sondern tritt erst durch die Aufführung ins Sein. «"103 Auch Federhofer verfolgt einen ähnlichen Formbegriff, der »etwas der Summe der Einzelwirkungen jener Elemente gegenüber völlig Neues, eine Einheit höherer Ordnung darstellt « ${ }^{104}$. Dieses Konzept finde, so Federhofer weiter, in der zeitgenössischen Musiktheorie nur unzureichenden Widerhall: Statt eines »musikalischen Verlauf[s], der von einem tonlich bestimmten Ausgangspunkt zu einem ebensolchen bestimmten Endpunkt hinzielt, [...] der hörmäßig keine Unterbrechung, keine Unterteilung verträgt", würde musikalische Form in gängigen Theorien »nicht als Ganzes, sondern nur als summatives Ereignis betrachtet und gewertet ${ }^{105}$.

Gleichwohl kritisiert Federhofer an Vorläufern seines Konzepts - neben Westphal benennt er etwa die energetischen Erklärungsmodelle Ernst Kurths ${ }^{106}$-, dass jene die Frage, welche Konsequenzen ein solches Konzept für die Analyse des musikalischen Satzes mit

100 Vgl. Utz 2016, 193-195, Zitate: 193f.

101 Vgl. Wörner 2014, 404-406.

102 Westphal 1935, 50.

103 Wörner 2008, 410.

104 Federhofer 1943, 1.

105 Ebd., 2.

106 Überhaupt hat die Kurth-Kritik eine lange Tradition unter den Anhängern Schenkers (vgl. Tan 2015, 100f.). Dass Kurth (1886-1946) für Schenkerianer eine Reibungsfläche darstellte, erklärt sich nicht zuletzt aus dem Umstand, dass beide prominente Figuren und damit unmittelbare Konkurrenten in einem Umbruchsprozess innerhalb der damaligen Musiktheorie waren, durch den vor allem energetische Ansätze in den Vordergrund drängten: »Die klassischen ıvertikalen tonalen und harmonischen Erklärungsmodelle befanden sich in der Krise. Man arbeitete an >linearen` Reformulierungen. (Holtmeier 2003, 21, Anm. 26). Rudolf Schäfke hält hierzu fest, dass Schenker »[a]m frühesten [...] die Energetik als geschlossenes System vertreten [hat] « und nennt ihn dabei in einem Atemzug unter anderen mit Kurth (vgl. Schäfke 1982, 393-396: Zitat: 396). Es sei hier nochmals daran erinnert, dass sich Guido Adler bei seiner Emeritierung dafür einsetzte, Kurth als seinen Nachfolger nach Wien zu berufen (siehe oben, Abschnitt Federhofers künstlerische und wissenschaftliche Ausbildung). 
sich bringt, entweder unbeantwortet gelassen oder gar die Sinnhaftigkeit analytischer Betrachtungen geleugnet hätten. So spricht Westphal in Bezug auf den ganzheitlichen Formverlauf von einem »Phänomen physiologisch-psychologischen Werdens [...], dem kein stoffliches Äquivalent zur Seite gestellt werden könnte « ${ }^{107}$. Auch Kurth stelle den Vorgang des Hörens und damit das sinnliche Erleben des musikalischen Verlaufs über die Analyse des diesem zugrunde liegenden musikalischen Satzes: Nur im Hören seien die maßgeblichen energetischen musikalischen Prozesse vollends wahrnehmbar, wobei Kurth, der den adäquaten Hörvorgang als einen mehrschichtigen Prozess auffasst ${ }^{108}$, diesen stark an das Subjektive zurückbinde: „Das individuelle musikalische Hören « wird für Kurth, so Federhofer, »durch die Anlage des einzelnen (Kunst)werkes konditioniert und bedingt sich durch das Erlebnis des Kunstwerkes, aber auch durch individuelle Erfahrung, Kunstverständnis und Reflexion - der Interpretation - des jeweiligen Rezipienten. « ${ }^{109}$ Ein tiefergehendes, objektives Aufdecken der energetischen Melodie- und Formverläufe durch das Mittel der Analyse sei in Kurths Konzept also letztlich nicht mitgedacht. ${ }^{110}$

Obgleich auch Federhofer durchgehend das »hörmäßige« Erfahren als zentralen Aspekt seines ganzheitlichen Formkonzepts betont, widerspricht er den Ansichten Westphals und Kurths, wonach die Formwahrnehmung sich nicht objektiv und gänzlich in der Analyse auflösen lässt, in seiner Habilitationsschrift vehement: "Weshalb sollte sich die Funktion der Einzelteile für das Verlaufsganze nicht in bestimmten stofflichen Beziehungen, eben jenen, von deren Vorhandensein, bezw. von deren Wirksamkeit das Zustandekommen des Ganzheitserlebnisses abhängig ist, nachweisen lassen? « ${ }^{111}$ Freilich sei es unmöglich, alle Teile der musikalischen Strukturen und thematischen Beziehungen beim Hören zur Gänze zu erfassen; im Mittelpunkt des ganzheitlichen Verlaufs stehe vielmehr ein »eigentliches Grundgerüst«:

[Die] sverzwickten thematischen Beziehungen verdanken ihre Existenz zum Großteil eben überhaupt nicht jener vorhin so gekennzeichneten intuitiven Denktätigkeit, sondern sind nur bewußt-konstruktive Auffüllung des eigentlich schöpferischen Entwurfs. [... $]^{112}$

Sein [des schöpferischen Entwurfs] Zustandekommen hängt daher in erster Linie auch gar nicht vom Teil ab, sondern von Zusammenhängen und Beziehungen, die erst durch die Folge der Teile entstehen, bezw. hörmäßig wirksam werden. [...] Sie stellen das Kunstwerk, dessen eigentliches Grundgerüst sie bilden, in verküruzter [sic] Überschau, in gleichsam zeitlicher Zusammenraffung dar [...]. ${ }^{113}$

107 So wiedergegeben in Federhofer 1943, 20, allerdings ohne Seitenangabe.

108 Kurth unterscheidet zwischen »energetische[m] «/»dynamische[m] « und »klangsinnlichem « Hören, die allerdings nicht scharf voneinander abgegrenzt werden können. Das senergetische` Hören bezeichnet die Fokussierung auf die Spannung, die beispielsweise einer Dissonanz im Hinblick auf eine zu erwartende Auflösung innewohnt. Die sklangsinnliche` Hörerfahrung verweilt dagegen auf dem »sinnlichherben Empfindungsreiz« (vgl. Wörner 2014, 213-215; Zitate: 213).

109 Federhofer 1943, 214.

110 Nach Meinung Schenkers verhielt es sich genau umgekehrt: "Statt durch das Ohr entschied nun Kurth seine Zweifel ganz einfach durch das Auge: hier gehen die Töne auf-, dort abwärts (andere Richtungen gibt es aber auch nicht) und flugs war die Theorie von der Bewegung an sich aufgestellt". (Schenker $1925,96)$ »Ich entsinne mich fast keines Beispieles unter den hunderten in seinem Buch, das richtig gehört und richtig wiedergegeben wäre.« (Ebd., 98)

111 Federhofer 1943, 18.

112 Ebd., 30.

113 Ebd., 32f. 
Dieses `Grundgerüst` erfahre nun eine horizontale Entfaltung auf mehreren Ebenen:

Die wahre Bedeutung des Grundgerüstes für den musikalischen Verlauf offenbart sich erst in der vollendeten Erscheinung des Kunstwerkes, denn das Tongeschehen verläuft nicht in einer, sondern gleichzeitig in verschiedenen Ebenen. Bestimmte besonders ausgezeichnete Klänge [...] stehen nicht nur zu den ihnen benachbarten Klängen in Beziehung, sondern verleihen darüber hinaus einem bestimmten tonlichen Verlauf einen übergeordneten Funktionswert [...]. Ein Tonvorgang zwischen zwei solchen Knotenpunkten stellt auf alle Fälle bereits eine Einheit dar, da der von einem Anfangs- zu einem Zielklang hin sich erspannende Verlauf hörmäßig keine Unterbrechung duldet, ohne eben das einzubüßen, was seinen eigentlichen (ganzheitlichen) Sinn ausmacht. ${ }^{114}$

Unterfüttert durch entsprechende Begrifflichkeiten, sind es also offenkundig Schenkers Theorien, die für Federhofer das einzig adäquate Werkzeug zum Erfassen ganzheitlicher Formverläufe darstellen. Schenkers Name fällt freilich kein einziges Mal. Erst als Federhofer den Text (unter demselben Titel, allerdings exklusive des letzten Kapitels) 1950 in seiner Aufsatzsammlung Beiträge zur musikalischen Gestaltanalyse veröffentlichte, konnte er in einer Fußnote enthüllen, dass der Arbeit die Theorien Schenkers zugrunde liegen beziehungsweise er jene einige Jahre zuvor mit Jonas studiert hatte. ${ }^{115}$

Zur Veranschaulichung wendet Federhofer in seiner Habilitationsschrift das Modell des ‘Grundgerüstes` auf den Beginn von Beethovens Klaviersonate E-Dur op. 109 und damit auf eines jener Werke an, denen Schenker bereits eine Erläuterungsausgabe ${ }^{116}$ gewidmet hatte und das er darüber hinaus im Freien Satz erwähnt ${ }^{117}$. Beide Analysen enthalten Reduktionsdarstellungen der eröffnenden Takte, deren Zusammenhang offenkundig ist (Bsp. 1). ${ }^{118}$
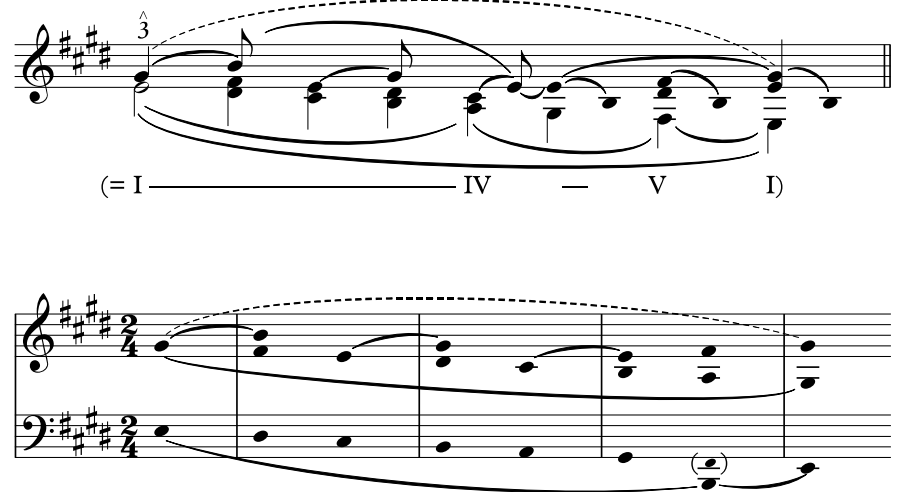

Beispiel 1a: Reduktion von Ludwig van Beethoven, Klaviersonate E-Dur Op. 109, Beginn: Heinrich Schenker (1956, Anhang, 59)

114 Ebd., 33f.

115 Vgl. Federhofer 1950, 39. Siehe oben, Anm. 54.

116 Schenker 1971 [1913].

117 Vgl. Schenker 1956, Notenband, 59.

118 Vgl. die jeweiligen Abbildungen in Heinrich Schenker 1956, Notenband, 3, beziehungsweise Federhofer 1943, 35. Die Ursachen für abweichende Details in den Darstellungen vieler Notenbeispiele sind schwer zu beurteilen. Teilweise sind sie um idiomatische, für die grundsätzlichen Erkenntnisse jedoch nebensächliche Elemente reduziert (etwa Schenkers Versetzung in die obligate Lage im BeethovenBeispiel, oder die detailliertere Bogensetzung in der H-Dur-Fuge von J.S. Bach; siehe unten). Unter der (nicht zuletzt durch diese Arbeit gestützten) Annahme, dass Schenkers Schriften auch während der NSZeit sehr wohl bekannt waren, ist dabei zumindest denkbar, dass Federhofer durch diese Änderungen die Plagiate zu verschleiern versuchte. Hierfür sind die Änderungen aber wohl zu gering ausgeprägt und erübrigen sich im Grunde bereits durch die eindeutige Bezugnahme in der Auswahl der Notenbeispiele. 
Es offenbart sich hier für Federhofer »die Erkenntnis jenes ganzheitlichen Verlaufes, der durch ein Streben charakterisiert ist, dessen Erfüllung im Erreichen eines hörmäßig besonders ausgezeichneten Zielklanges liegt « ${ }^{119}$. Etwas später präzisiert er analytisch:

Worin liegt nun der Sinn der Bewegung, die Ganzheit des Ablaufs beschlossen? In nichts anderem, als der mit Hilfe von stufenweisen Durchgängen erfolgten "Auskomponierung" des E-Klanges, wobei unter Auskomponierung ganz allgemein die Möglichkeit der Dehnung eines Klanges durch Horizontalisierung, also die Umsetzung räumlichen Geschehens in zeitliches verstanden werden soll. ${ }^{120}$

Der sorglose, meist nur durch Apostrophierung betonte Umgang mit Schenkers Terminologie und Techniken durchzieht alle Analysen von Federhofers Arbeit, ohne dass jemals über deren Ursprünge, bisweilen auch nur ihre genaue Bedeutung aufgeklärt würde. In Bezug auf das genannte Beethoven-Beispiel wird etwa noch das Vorhandensein eines „Oktavzuges « in parallelen Terzen (in Federhofers Skizze in ihrer originalen Lage als Dezimen e/gis ${ }^{1}$ bis E/gis) genannt, wobei Federhofer in Bezug auf das im Bassgang angenommene, aber nicht real erklingende Fis erklärt, dass »wir ihn [den Ton Fis] vorempfindend im Sinne der eingeschlagenen Bewegungsrichtung des sich über den Raum einer Oktave erstreckenden Tonzuges als vikariierenden Ton für Fis [auffassen] « ${ }^{121}$ - eine in Schenkers Analysen häufig anzutreffende Methode. ${ }^{122}$ Auch die Bestimmung des "Übergreiftones« ( $h^{1}$ in T. 1 als Oberterz zu gis ${ }^{1}$ ), »der es ermöglicht, daß nach zweimaliger terzweiser Brechung abwärts von e1 aus gis1 wiedererreicht werden kann « ${ }^{123}$, haben die beiden Analysen gemein (Schenker spricht allerdings von "ausgeworfenen Terzen", durch welche die Lage beibehalten werde, »die sonst durch den Abwärtszug zu tief geraten würde « ${ }^{124}$ ). Dies wird in beiden Skizzen durch dieselbe strichlierte Kurve angedeutet. Durch diese Beibehaltung der originalen Methodik und Terminologie unterscheidet sich Federhofers Schenker-Rezeption wesentlich von jener Bernhard Martins (siehe unten).

Ein anderes Beispiel, das Federhofer zur Veranschaulichung sseines، Zugangs heranzieht, betrifft das Thema der H-Dur-Fuge aus dem zweiten Band des Wohltemperierten Klaviers. Auch hierzu existiert eine Besprechung Schenkers, welche Federhofer weitestgehend in seine Habilitationsschrift übernimmt: Beide Analysen verwenden das Thema nämlich als Anschauungsobjekt für ihre - wenig überraschend gleichlautende - Kritik an einer entsprechenden Analyse Ernst Kurths.

Schenkers Analyse ist eingebettet in einen Aufsatz über das Präludium aus der Partita E-Dur BWV 1006 von Johann Sebastian Bach, die im ersten Jahrgang des Meisterwerks in

119 Federhofer 1943, 35.

120 Ebd., 36.

121 Ebd. An anderer Stelle (ebd., 38, Anm.) hält Federhofer hierzu allgemein fest: »Gerade jene Töne, die eigentlich 'gemeint`, also in unserer Tonvorstellung wirksam sind, in der realen Ausführung jedoch nicht angetönt werden, sind geeignet, ein hohes Maß von Spannung hervorzurufen. «

122 Das vielleicht bekannteste Beispiel stellt Schenkers Analyse der Überleitung zum Seitenthema im Kopfsatz aus Beethovens Fünfter Sinfonie dar (T. 60-64), in der er postuliert, »daß im Leitspruch des zweiten Gedankens der Ton b des T. 62 eigentlich für d1 steht«, wodurch »der verborgene Sekundschritt es1-d1 wie in den T. 15 ff zum Quartknotenpunkt hinaus [drängt] « (Schenker 1922a, 32).

123 Federhofer 1943, 36.

124 Schenker 1956, 162. 
der Musik erschien. ${ }^{125}$ In diesem Text setzt sich Schenker ausführlich mit Kurths BachAnalysen auseinander. Das teils vernichtende Urteil gründet weniger auf einer Widerlegung von Kurths analytischen Schlüssen als auf der Schenkers Meinung nach unzureichenden Methodik und der nichtssagenden Terminologie, mit der Kurth heikle analytische Stellen bisweilen übergehe:

Dieses ständige geflissentliche Ausweichen vor jeglicher Bestimmtheit in Begriff und Wort ergibt sich dem Verfasser [Kurth] aus seiner Grundanschauung, daß die Melodik (»Linie«, »Ausspinnung «) eine selbsttätige Kraft sei [...]. Freilich führt Kurth in seinen Liniendeutungen je nach der Verlegenheit auch vertikale Begriffe durch Hintertürchen heran, so wie sie nur aber (seiner Meinung nach) ihre Schuldigkeit getan haben, vergißt er sie, leugnet sie, und so pendelt seine Deutung ständig zwischen Zugeben und Leugnen klanglicher Grundlagen und bleibt im Unbestimmten wie der Grundgedanke überhaupt. ${ }^{126}$

Auch Federhofer erhebt den Vorwurf der Unbestimmtheit: Kurth beschränke sich lediglich darauf, „das Musikalische als psychische Strömung und senergetischen`Vorgang darzustellen, wobei er die gestalthafte Fundierung außeracht lässt [...]. Sie [Kurths Analyse] beläßt - und diese Feststellung ist wesentlich - den musikalischen Vorgang in seiner tonlich-einmaligen Besonderheit weitgehend unbestimmt. « ${ }^{127}$ Auch die Kurths Auffassung entgegengestellte Analyse verrät Schenker unzweifelhaft als Bezugspunkt, was schon die Reduktionsskizzen (Bsp. 2), vor allem aber die verbalen Erläuterungen verraten. Diese sind im Folgenden zur Verdeutlichung der Übereinstimmung gerade in markanten Details (»Erfüllung «; »Leittonspannung « im Quartzug) bewusst ausführlich wiedergegeben:

Hier liegt die Erfüllung des Dur-Dreiklanges $\mathrm{H}$ vor, siehe bei a). Diesmal beliebt es Bach, die Auskomponierung auf den Wegen des obligaten dreistimmigen Satzes zu leiten, wie das Bild bei b) zeigt. Die Oberstimme durchmißt den Quartraum des Klanges von fis bis $\mathrm{h}$ - der Quartraum ist ein durchaus Bestimmtes, eine größere Stimmführungseinheit, die auch Kurths »Leittonspannung « in sich enthält - und die Unterstimme legt den Terzzug H-dis zurück. Um im Durchgang den Ausgleich zwischen den vier Tönen des Quartzuges und den drei Tönen des Terzzuges herbeizuführen, um auch die 5-5-Folgen zu vermeiden, die durch die gerade Bewegung beider Züge drohen, wird die 5-6-Auswechslung zuhilfe genommen. ${ }^{128}$

Indem wir dieses gis nach vorwärts in Beziehung zum Leitton ais und h setzen, wird jenes fis auch horizontal verständlich als Ausgangspunkt einer Linie, die in stufenweisem Anstieg den Quartraum fis-h des H-Klanges durchmißt. Zu gleicher Zeit legt die durch die akkordliche Verdichtung auch sichtbar in Erscheinung tretende untere Linie den Terzraum H-dis zurück. Anfangs- und Zielklang ist der H-Dur-Dreiklang, dessen Übergang aus der Quint- in die Terzsextlage das Thema formt; auf die Gewinnung dieser Lage zielt der Tonvorgang als ıgerichtete` Größe hin und gerade die Zielbewußtheit verleiht ihm jenen ganzheitlichen Charakter, der in diesem Falle durch die Auskomponierung des $\mathrm{H}$-Klanges vermittels eines aufwärtssteigenden »Quartzuges« in einer durch die akkordliche Verdichtung sichtbar in Erscheinung tretenden Oberstimme und eines »Terzzuges« in der ihr entsprechenden Unterstimme bewirkt wird. Der Quartzug enthält auch die Leittonspannung ais-h in sich als letztes und konzentriertes Streben nach Erfüllung des H-Klanges. ${ }^{129}$

125 Schenker 1925.

126 Ebd., 95.

127 Federhofer 1943, 24 (Ergänzung des Verfassers).

128 Schenker 1925, 97.

129 Federhofer 1943, 38f. Die »5-6-Auswechslung« ist bei Federhofer zwar nicht explizit benannt, jedoch wesentlicher Bestandteil der Skizze. 


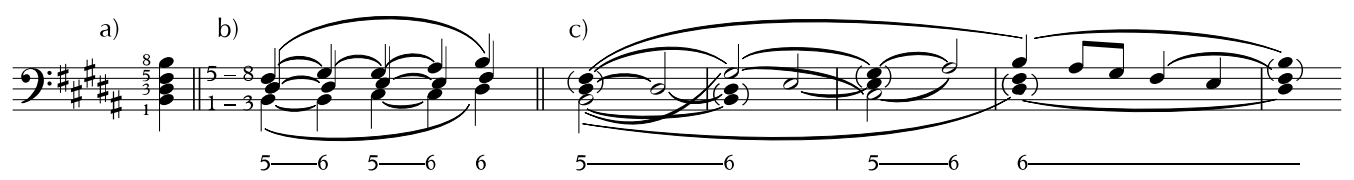

Beispiel 2a: Reduktion von J.S. Bach, Das Wohltemperierte Klavier, Bd. 2, Fuge H-Dur BWV 892: Heinrich Schenker $(1925,97)$

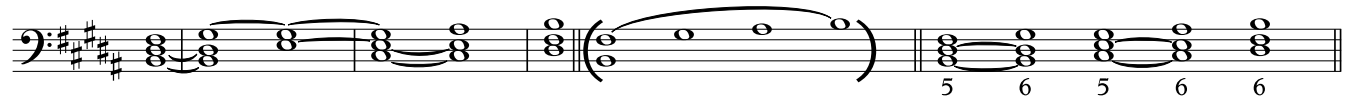

Beispiel 2b: Reduktion von J.S. Bach, Das Wohltemperierte Klavier, Bd. 2, Fuge H-Dur BWV 892: Hellmut Federhofer $(1943,38)$

Auch für das Bemühen um gesamtformale Erkenntnisse stellt Schenker Federhofers wesentlichen Bezugspunkt dar. Die entsprechenden Parallelen lassen sich anhand des Kopfsatzes der Klaviersonate a-Moll KV 310 von W.A. Mozart aufzeigen, dem einerseits Schenker eine Analyse gewidmet hat ${ }^{130}$ und den andererseits Federhofer für eine von drei ausführlichen Analysen in seiner Habilitationsschrift auswählt (neben Präludium und Fuge D-Dur aus dem ersten Band des Wohltemperierten Klaviers sowie dem ersten Intermezzo aus Brahms' Klavierstücken op. 118). Wieder decken sich die Betrachtungen über weite Strecken, was vor allem in der Gegenüberstellung der sowohl von Schenker als auch Federhofer angefertigten Reduktionstafeln deutlich wird ${ }^{131}$ (Bsp. 3).

Folgt man Federhofers Text zum Kopfsatz der Mozart-Sonate und mit ihm den Reduktionen, welche im Wesentlichen übereinstimmende Ergebnisse widerspiegeln (von Details in der Darstellung abgesehen), tritt Schenkers Vorbildwirkung klar zutage. Nur an wenigen Stellen weichen die Analysen voneinander ab: So sieht Schenker im Kern des zweiten Gedankens einen zweigeteilten Oktavzug (T. 23-31 und 32-35), dessen erste Hälfte einem unvollkommenen $\left(e^{2}\right)$, die zweite Hälfte dagegen einem vollkommenen Ganzschluss $\left(c^{2}\right)$ entgegendrängen; das nicht erklingende, für den Abschluss folglich wieder nur mitgedachte $c^{2}$ rechtfertigt Schenker durch die unmittelbare Wiederholung des gerade durchschrittenen Oktavzugs. ${ }^{132}$ Federhofer findet hier zu einer anderen Interpretation, wobei er mit seinem Verweis auf die unbefriedigende "Abschlußwirkung" in Takt 35 auf Schenkers Analyse hinzuweisen scheint, ohne ihn allerdings zu benennen:

Eine befriedigende Abschlußwirkung wird in T. 35 nicht erzielt, und zwar aus dreierlei Gründen. Erstens wird der Zielton c2 verschwiegen, zweitens fehlt der Unterstimme die vorher schon berührte richtige Baßlage, und drittens hat der zweimalig abrollende Terzzug g2-e2 eine derart breite Dehnung im Vordergrunde erfahren, daß sich ihm gegenüber der nur einmal in gedrängter Form abrollende Quintzug keineswegs durchzusetzen vermag. ${ }^{133}$

130 Schenker 1922c.

131 Die Tafeln der Habilitationsschrift sind allerdings nicht erhalten; sie waren der Schrift offenbar nicht direkt beigefügt und haben möglicherweise nur als lose Blätter existiert. Erst sieben Jahre später finden sich die Tafeln im Anhang der Beiträge zur musikalischen Gestaltanalyse (Federhofer 1950, [95]-[97]), wobei aufgrund der zahlreichen Beispiele und Verweise im Text zweifelsfrei feststeht, dass es sich um dieselben Abbildungen handelt.

132 »In T. 35 darf die erste Sechzehntelpause für den Schlußton c2 stehen, da schon beim zweiten Sechzehntel der Oktavzug mit c3 an der Spitze zur Wiederholung gebracht wird.« (Schenker 1922c, 9)

133 Federhofer 1943, 60f. 


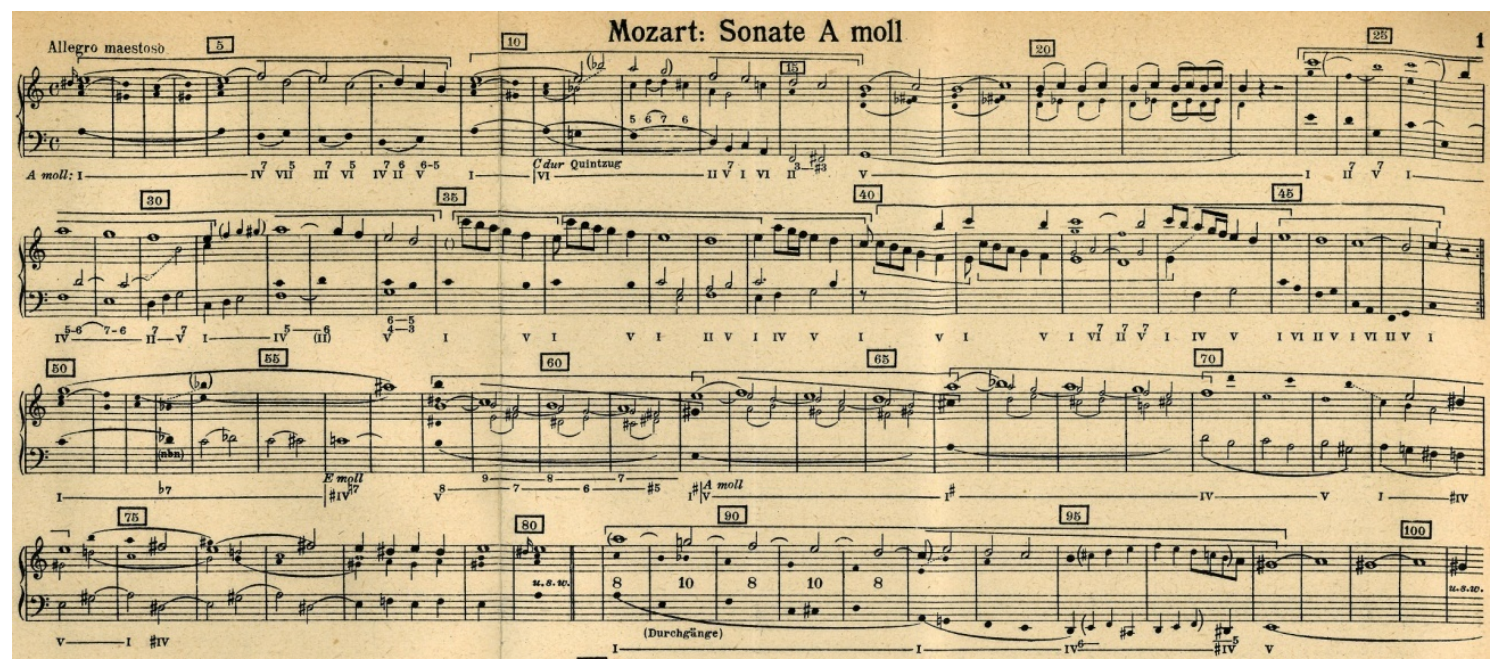

Beispiel 3a: W.A. Mozart, Klaviersonate a-Moll KV 310, erster Satz, Urlinientafel: Heinrich Schenker (1922c, Anhang)
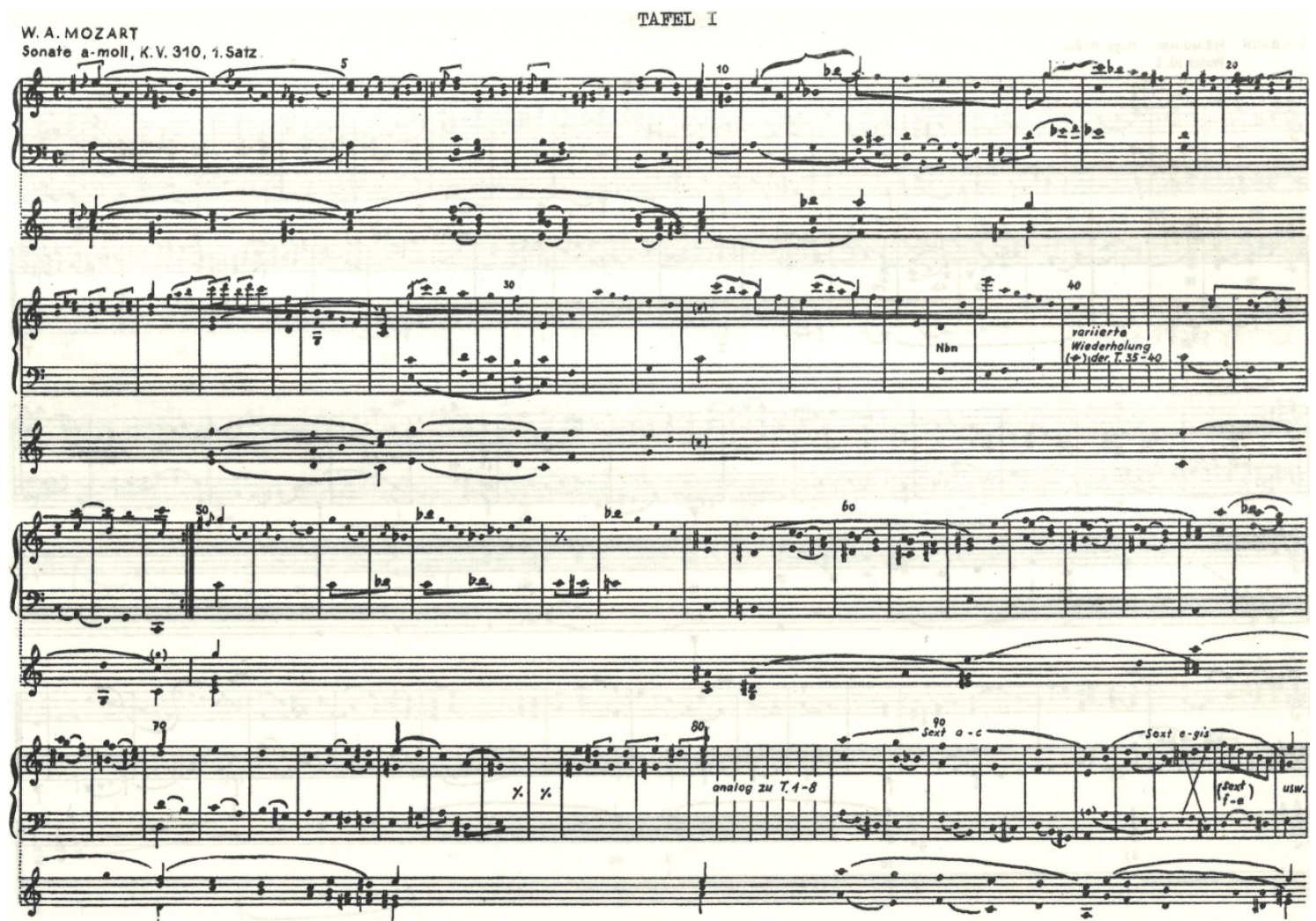

Beispiel 3b: W.A. Mozart, Klaviersonate a-Moll KV 310, erster Satz, Urlinientafeln: Hellmut Federhofer (1950, Anhang)

Da Federhofer einige Jahre später in den Beiträgen zur musikalischen Gestaltanalyse darauf hinwies, dass er die Analysen der Habilitationsschrift bereits in Wien »unter Anleitung " ${ }^{134}$ von Jonas entworfen habe, könnte diese Abweichung (gemeinsam mit einigen weiteren) auch direkt auf diese gemeinsame Arbeit zurückzuführen sein. Wie der nach

134 Siehe oben, Abschnitt Federhofer und der Schenker-Kreis (Anm. 54). 
Kriegsende zwischen Federhofer und Jonas geführte Briefverkehr belegt ${ }^{135}$, tauschten sie sich intensiv über Schenkers Analysen aus und monierten bisweilen "gewisse Schlampereien, die es bei Schenker eben gibt « ${ }^{136}$.

In Anbetracht der damaligen (wissenschafts-)politischen Umstände eröffnet sich nun aber die Frage, weshalb Federhofers Arbeit trotz ihres unleugbaren Bezugs zu Schenker ganz offensichtlich keinerlei Anstoß erregte, welche Rolle Werner Danckert in diesem nach den damaligen Regularien sillegalen Habilitationsprozess spielte, und wie dieser ,Grazer Fall in die reichsweite Schenker-Zensur einzuordnen ist.

Wie etwa die Arbeiten Ludwig Holtmeiers ${ }^{137}$ und Nicholas Cooks ${ }^{138}$ zeigen, wurden Schenkers Theorien in Deutschland bereits vor 1933 durchaus weit gestreut rezipiert, was "suggests that Schenker's profile was higher than his mythologisation as unrecognised genius would have it. «"139 Schon bald nach 1900 wurden Schenkers Schriften publizistisch reflektiert; die Schenker-Schüler Otto Vrieslander und Herman Roth setzten sich mit ihm in eigenen Werken ebenso auseinander wie etwa Wilhelm Maler, Hermann Grabner (wie Federhofer gebürtiger Grazer und Schüler Suchslands) oder Karl Blessinger. Ferner veröffentlichte auch Jonas während seiner Zeit in Berlin fünf Aufsätze zu Schenker in der Allgemeinen Musikzeitung. ${ }^{140}$ Auch an mehreren Universitäten verfolgte man Schenkers Wirken aufmerksam, wie die Subskription des Tonwillens durch zehn entsprechende deutsche Musikinstitute für die Zeit 1924-25 belegt. ${ }^{141}$

Nach 1933 verschwand der Name Heinrich Schenkers wie der anderer inkriminierter Kollegen weitestgehend aus dem deutschen musiktheoretischen Schrifttum. ${ }^{142}$ Die höchst effektive Zensur wurde dadurch gewährleistet, dass man als Buchautor Mitglied der Reichsschrifttumskammer (RSK) sein musste, welche jede Veröffentlichung vorab zu genehmigen hatte. Wohl aus diesem Grund unterbrach Felix-Eberhard von Cube die um 1934 begonnene Arbeit an seinem auf Schenker basierenden Lehrbuch der musikalischen

135 Aus dem Nachlass Hellmut Federhofers liegen dem Autor Kopien von Briefen Jonas' vom 16. Januar 1961 sowie zwei weiterer ohne Jahresangabe (13. Oktober; 23. Mai) vor, die aber aufgrund inhaltlicher Zusammenhänge wohl aus dem näheren zeitlichen Umfeld des ersten Briefes stammen.

136 Brief von Oswald Jonas an Hellmut Federhofer vom 13. Oktober ohne Jahresangabe.

137 Vgl. Holtmeier 2003, 17.

138 Vgl. Cook 2007, 269-276.

139 Ebd., 272.

140 Vgl. Koslovsky 2014, 155. In einem Brief an Salzer kommentierte Schenker die Veröffentlichung von Jonas 1933 (»Heinrich Schenker«) vor dem Hintergrund der zunehmenden antijüdischen Stimmung, welcher Jonas 1934 schließlich auch weichen musste: »Hat Ihnen Dr. Jonas seinen Aufsatz über mich übermittelt, den er - horribile dictu: ein Jude über einen Juden ausgerechnet in Berlin [...] gebracht hat? - eine vortreffliche Studie. (Brief von Heinrich Schenker an Felix Salzer vom 24. September 1933; Schenker Documents Online, http://www.schenkerdocumentsonline.org/documents/correspondence/FS40-1_17.html [30.6.2018]).

141 Vgl. Cook 2007, 274.

142 Allerdings wurde Schenker im Lexikon der Juden in der Musik (Berlin 1940) fälschlicherweise nur als 'Halbjude bezeichnet - für William Drabkin Ausdruck des Bewusstseins, wie nahe Schenkers politische Ansichten der nationalsozialistischen Ideologie standen, was beispielsweise im Aufsatz Von der Sendung des Deutschen Genies aus dem ersten Jahrgang des Tonwille überdeutlich zum Ausdruck kommt; vgl. Drabkin 1986, 189 f. 
Kunstgesetze. ${ }^{143}$ Die wenigen Ausnahmen an sneuen`, das heißt: zwischen 1933 und 1945 erstveröffentlichten Schriften, in denen sich Namen unerwünschter Theoretiker finden, verdanken sich folglich bestimmten `Systemlücken`. Ein Beispiel hierfür stellt Heinz Ludwig Deneckes 1937 verfasste Dissertation dar, in welcher sich der Autor mit den Theorien Schenkers und Kurths auseinandersetzen konnte, da rein wissenschaftliche Publikationen der RSK nicht vorgelegt werden mussten. Demgegenüber lässt sich Michael Dachs' Kontrapunkt von 1941 schlicht durch Nachlässigkeit erklären: Dachs dürfte übersehen haben, dass er zur Mitgliedschaft in der RSK (statt nur in der Reichsmusikkammer) verpflichtet gewesen war, als er sein Buch veröffentlichte. Auch der Verlag verabsäumte eine entsprechende Meldung, weshalb es zu einer Abmahnung, letztlich aber keinem Verbot der Publikation kam. ${ }^{144}$ Den bemerkenswertesten Fall lieferte aber sicher Bernhard Martin, der mit Schenker zwischen 1929 und 1933 zu Fragen des Theorieunterrichts in losem brieflichen Kontakt stand. Wie mehrere Einträge in Schenkers Tagebuch verraten, übersandte ihm der "wackere[ ] Lehrer in Bottrop " ${ }^{145}$ mehrfach Analysen (Schenker spricht von »Urlinien«, »Urlinie-Bild« bzw. »Urlinie-Blätter[n] « ${ }^{146}$ ) zur Durchsicht. In Martins Untersuchungen zur Struktur der "Kunst der Fuge» J.S. Bachs von 1941 wird gleich in der Einleitung mit folgendem Wortlaut auf Schenker verwiesen:

Als System wurde dieses Prinzip [Bedeutung der Raumordnung] für die Musik zuerst von Heinrich Schenker (Jude) aufgestellt. Schenker hat freilich in der ihm eigentümlichen Weise Technik und Methode seines »Ursatzes « so sehr überspitzt, daß verantwortungsvolle Hüter der deutschen Kunst, denen der letzte Sinn des von ihm erörterten Problems im bunten Gewirr der Einzelheiten nicht aufgehen konnte, sich von seiner Lehre abwandten und darüber hinaus in Ermangelung besserer Einsicht in die Bedeutung der musikalischen Raumgestaltung überhaupt ein für den Stil einer Komposition so wichtiges Prinzip wieder ganz aus den Augen zu verlieren scheinen. ${ }^{147}$

Der (gerade im letzten Teil des Zitats) gar nicht so subtile Spott dieser Passage ${ }^{148}$ verblüfft umso mehr in Anbetracht des Umstands, dass die Untersuchungen als vierter Band der Kölner Beiträge zur Musikforschung herausgegeben wurden, für welche der während der NS-Zeit einflussreiche Karl Gustav Fellerer (1902-1984) verantwortlich zeichnete, der unter anderem enge Verbindungen zu Herbert Gerigk unterhielt. ${ }^{149}$ Neben diesen Sonderfällen sind jene (freilich auch nicht zahlreichen) vor 1933 erschienenen Werke zu nen-

143 Vgl. ebd., 194. Cubes Lehrbuch erschien erstmals 1988 in einer englischen Übersetzung unter dem Titel The Book of the Musical Artwork. An Interpretation of the Musical Theories of Heinrich Schenker (Cube 1988).

144 Für beide Fälle vgl. Holtmeier 2003, 23, Anm. 31.

145 Brief von Heinrich Schenker an Emil Hertzka vom 19. Dezember 1929; Schenker Documents Online, http://www.schenkerdocumentsonline.org/documents/correspondence/WSLB-418-1.html (30.6.2018).

146 Vgl. etwa Schenkers Tagebucheinträge vom 25. Juli 1931 (http://www.schenkerdocumentsonline.org/ documents/diaries/OJ-04-04_1931-07/r0027.html [30.6.2018]; 7. Dezember 1931 (http://www.schenker documentsonline.org/documents/diaries/OJ-04-05_1931-12/r0007.html [30.6.2018] und 19. Juni 1931 (http://www.schenkerdocumentsonline.org/documents/diaries/OJ-04-04_1931-06/r0019.html [30.6.2018]).

147 Martin 1941, 14.

148 Es handelt sich jedenfalls um ein (möglicherweise sprachliches) Missverständnis, wenn David Carson Berry sich auf Martins Untersuchungen bezieht und festhält, dass »Schenker is mentioned in the ,Einleitung، [`Introduction`] only to insult his work« (Berry 2004, 435; Einfügung original). Drabkin charakterisiert die betreffenden Zeilen sicher zutreffend als »politically >sensitive` foreword« $(1986,190)$.

149 Vgl. Haken 2017. 
nen, in deren Neuauflagen während der NS-Zeit eigentlich sunerlaubte ‘ Namen (bewusst oder unabsichtlich) stehen blieben. Wesentlich schwerer tat sich die nationalsozialistische Zensur schließlich mit Schriften, die sich auf inkriminierte Autor*innen stützten, ohne jene aber zu benennen. Hierzu können im Falle Schenkers etwa einzelne Aufsätze des erwähnten Bernhard Martin gezählt werden, der die von ihm übernommenen Methoden Schenkers (im Gegensatz zu Federhofer) mit einer beinahe gänzlich neuen Terminologie versieht ${ }^{150}$, aber auch die Kurth-Rezeption bei Hermann Grabner liefert ein prominentes Beispiel. ${ }^{151}$

Vor diesem Hintergrund kann mit an Sicherheit grenzender Wahrscheinlichkeit ausgeschlossen werden, dass Danckert Schenkers Arbeiten nicht gekannt hätte: Zum einen weisen ihn frühere Arbeiten als einen Kenner des Energetik-Diskurses aus, was etwa in seinen angesichts des Veröffentlichungszeitpunkts 1934 überraschend milden Ausführungen zu Kurth in den Beiträgen zur Bachkritik zum Ausdruck kommt. ${ }^{152}$ Zum anderen ergaben Recherchen in der Bibliothek des Grazer Instituts für Musikwissenschaft, dass in den ersten Jahren nach Gründung des Instituts und damit während der NS-Zeit einige zentrale Werke Schenkers angeschafft wurden. In seiner Institutsbibliothek hatte Danckert demnach Zugriff auf Schenkers Beethovens Neunte Sinfonie (erworben 1940), die Harmonielehre und den Kontrapunkt (erworben 1941) sowie sämtliche Ausgaben des Tonwillens (erworben 1942/43), daneben aber etwa auch Kurths Grundlagen des linearen Kontrapunkts (1917; erworben 1942). ${ }^{153}$

Es muss also davon ausgegangen werden, dass der hochgradig opportunistische, aber keineswegs überzeugt antisemitische Danckert die Theorien Schenkers in Federhofers Studie sehr wohl identifizierte, jedoch eine Intervention unterließ. Führt man sich übrigens die große Verbreitung energetisch orientierter Musiktheorien in den 1930er Jahren vor Augen, die sogar bis in hohe nationalsozialistische Kreise etwa um Fritz Jöde reich$t^{154}$, so könnte Federhofers Arbeit gerade mit ihren Akzenten auf ganzheitlichen Wahrnehmungsprozessen auf aktiven Zuspruch seines Betreuers gestoßen sein. Gleichzeitig ließe sich so auch erklären, wieso Kurth in der Habilitationsschrift relativ häufig genannt wird. Als rein pragmatische Überlegung mag man ergänzen, dass Danckert an seinem unbedeutenden Institut am Rande des Deutschen Reichs wohl selbst im Falle geringer Sympathie für Federhofers Arbeit nicht daran gedacht haben dürfte, mit einer allzu strengen

150 Beispiele hierfür sind Begriffe wie »Kletternote«, »Unterterzfältchen« oder »führender Raum« als Ersatz für Schenkers »Übergreifton«, »(Terz-)Ausfaltung« und »obligate Lage«, während er demgegenüber etwa die Kürzel »Nbn« (Nebennote) und »Dg« (Durchgang) beibehält (vgl. Drabkin 1986, 190-192).

151 Vgl. Holtmeier 2003, 23, Anm. 31.

152 Hier heißt es etwa: »Man kann den bekannten Analysen Ernst Kurths, ohne ihnen bemerkenswerte Einfühlungskraft und Feinspürigkeit absprechen zu wollen, doch den Vorwurf nicht ersparen, daß sie dieses Kardinalprinzip Bachscher Gestaltung verfehlen und Bachs Werk künstlich in den Bereich des transzendentalen Idealismus rücken und insofern grundsätzlich verzeichnen [...]. Man muß diese Feststellung einmal - bei aller Würdigung der vielfältigen Verdienste Kurths um eine lebendige MusikAuslegung - um ihrer grundsätzlichen Bedeutung willen aussprechen. (Danckert 1934, 14)

153 Das bedeutet wiederum, dass die genannten Werke bereits unter Birtner angeschafft worden waren. Birtners Schriften weisen dabei (wenigstens im Titel) nicht darauf hin, dass er sich jemals mit Schenker befasste. Es besteht demnach ein nicht unberechtigter Grund zur Annahme, dass Federhofer an diesen Anschaffungen beteiligt war; für sein Habilitationsverfahren musste er ja schon vor 1943 mit dem Institut in Kontakt gestanden haben. Die Provenienz der Bücher ist jedenfalls völlig unklar; möglicherweise stammten sie sogar aus Federhofers Privatbesitz.

154 Vgl. Schäfke 1982 [1934], 394-398. 
Auslegung der ideologischen Vorgaben einem umfassend geschulten und vielversprechenden Kandidaten zu schaden, wie er für damalige Grazer Verhältnisse sicher als Ausnahmeerscheinung anzusehen war. ${ }^{155}$ Diese Annahme wird abschließend auch durch einen Brief gestützt, den Danckert, offenbar als Teil eines nach dem Krieg über längere Zeit aufrecht erhaltenen Briefverkehrs, 1948 an Federhofer sandte: „Mit einem Sonderdruck Ihres Schenker-Aufsatzes würden Sie mich erfreuen « ${ }^{156}$. Obgleich man dieser knappen Äußerung im Hinblick auf Danckerts Meinung zu Schenker nur wenig Gewicht beimessen darf, belegt sie wenigstens, dass zwischen den beiden die Theorien Schenkers immerhin zur Sprache kamen und nicht aufgrund einer feindseligen Haltung Danckerts umgangen wurden, wie überhaupt das ganze Schreiben ein sehr gutes Verhältnis zwischen den beiden Briefpartnern belegt.

\section{DIE MUSIKTHEORIE HEINRICH SCHENKERS UND BEITRÄGE ZUR MUSIKALISCHEN GESTALTANALYSE}

In jedem Fall legte die Habilitationsschrift den Grundstein für Federhofers weitere Beschäftigung mit Heinrich Schenker. Durch sein Engagement war er (nach Einschätzung Nicholas Cooks) noch weit vor Kollegen wie Karl-Otto Plum und Franz Eibner »until 1991, when Martin Eybl was appointed to the University of Vienna, the only postwar Schenkerian scholar[] in the German-speaking countries to attract international attention « ${ }^{157}$. Wie Oliver Schwab-Felisch ergänzend feststellt, war Federhofer »über viele Jahre hinweg für nahezu jede deutschsprachige Rezension von Schenker-Literatur verantwortlich ${ }^{158}$. Insgesamt blieb sein Einsatz aber, letztlich wohl seines Gegenstands wegen ${ }^{159}$, bedauerlich wirkungslos. ${ }^{160}$ Statt durch Federhofers Fürsprache wurde gerade die westdeutsche Schenker-Rezeption seit den 1960er Jahren vielmehr von Carl Dahlhaus' kriti-

155 Während der NS-Zeit ist neben Federhofers Habilitationsschrift überhaupt nur mehr Artur Henkels Dissertation Die spekulative Musikanschauung des Novalis (1941) als Abschlussarbeit bestätigt worden. Henkel (1915-2005), Literaturwissenschaftler, 1958-1980 Ordinarius an der Ruprecht-Karls-Universität Heidelberg und 1993 mit der Goldenen Goethe-Medaille der Goethe-Gesellschaft Weimar ausgezeichnet, war zusammen mit Birtner aus Marburg nach Graz gekommen und hatte hier eine Stelle als wissenschaftliche Hilfskraft inne. Er scheint Graz aber schon bald nach seiner Promotion wieder verlassen zu haben (vgl. Flotzinger 1990, 51 und 54).

156 Brief Danckerts an Federhofer vom 18. März 1948 (Fotokopie im Besitz des Autors).

157 Cook 2007, 275.

158 Schwab-Felisch 2005b, 243.

159 Immer wieder wurde gefragt, weshalb sich die Rezeption der Theorien Schenkers im deutschen Sprachraum nach 1945 (und im Grunde bis heute) als so zäh erweist. Der Verweis auf die nationalsozialistische Zensur zwischen 1933/1938 und 1945 sowie die damit verbundene Emigration wesentlicher Schenker-Apologeten alleine greift jedenfalls zu kurz. Wie Holtmeier richtig festhält, ist vielmehr herauszustreichen, dass Schenkers »oft unerträglich primitive Sprache, der aggressive Tonfall im Tonwille, seine radikale deutsch-nationale Gesinnung und seine sich ereifernde Opposition gegen die Neue Musik [...] ihn in den Augen vieler geradewegs ins Lager der Nazis gestellt [haben] [...] Das Dritte Reich hat dazu geführt, daß in Deutschland der Politiker Schenker den Theoretiker auslöschen konnte.« (Holtmeier 2003, 21, Anm. 26).

160 Dies gilt im Grunde auch für die späteren Arbeiten Federhofers, die mit Schenkers Theorien in Verbindung stehen. Seine biographischen und Quellenstudien, die er in den beiden Büchern Heinrich Schenker. Nach Tagebüchern und Briefen (Federhofer 1985) und Heinrich Schenker als Essayist und Kritiker (Federhofer 1990) darlegte, gelten demgegenüber bis heute als Standardwerke der Schenker-Biographik. 
scher Haltung bestimmt. ${ }^{161}$ Es konnte dementsprechend nicht ausbleiben, dass sich auch hierzu Federhofer und Dahlhaus Anfang der 1980er Jahre einen Disput lieferten. ${ }^{162}$

Da Federhofers Habilitationsschrift erst 1950 als Teil der kleinen Sammlung Beiträge zur musikalischen Gestaltanalyse veröffentlicht wurde, kann sein kurzer Aufsatz »Die Musiktheorie Heinrich Schenkers « ${ }^{163}$ aus dem Jahr 1947 mindestens im deutschsprachigen Raum als eigentlicher Beginn der Schenker-Rezeption nach dem Zweiten Weltkrieg gelten. Der sachliche Stil des Textes überrascht nicht nur aus heutiger Perspektive, in der Federhofer gerade in seinen Schenker-Texten häufig als erbarmungsloser Polemiker erscheint, sondern auch in der Gegenüberstellung mit dem Tonfall des ehemaligen Schenker-Kreises vor 1938. Den verklärenden Tendenzen, wie sie nach dem Krieg Heinrich Hartmann ${ }^{164}$ und vor allem Hans Wingert ${ }^{165}$ beibehielten, tritt Federhofer hier mit einer zurückhaltenden und ausschließlich auf technische Aspekte fokussierten Darstellung gegenüber, welche die ideen- und zeitgeschichtlichen Kontexte der Theorien Schenkers (wiederum im Gegensatz zu Hartmann und Wingert) nur am Rande streift ${ }^{166}$ (siehe unten). Da er dabei eng an Schenkers eigenen Konzepten und Begriffen verbleibt, distanziert er sich gleichzeitig auch von jener amerikanischen Strömung, »[which] positioned the sconcept of tonalitys as the central concern of the Schenkerian enterprise ${ }^{167}$. Diese über Schenkers Theorien hinausgehende Akzentuierung ${ }^{168}$ wurde, wie Koslovsky auf-

161 Vgl. Schwab-Felisch 2005a, 369.

162 Als Reaktion auf Federhofers Akkord und Stimmführung in den musiktheoretischen Systemen von Hugo Riemann, Ernst Kurth und Heinrich Schenker (Federhofer 1981) veröffentlichte Dahlhaus seinen Aufsatz Im Namen Schenkers (Dahlhaus 1983), worauf Federhofer mit Im Namen Schenkers: Eine Erwiderung (Federhofer 1984) reagierte. Auch Karl-Otto Plum (1984) antwortete kritisch auf Dahlhaus' Text.

163 Federhofer 1947/2013.

164 Für Hartmann stellt Schenkers Arbeit »die klassische Musiktheorie» dar (২klassisch als vorwagnerianisch definiert); bei einer Betrachtung seiner Analysen sei »die Überlegenheit der Schenker'schen Methode sofort klar zu erkennen. Während alle vor Schenker nur den Vordergrund betrachtet haben und mit ihren Analysen natürlich zu den abenteuerlichsten Schlüssen kommen mußten, ist es Schenker als ersten [sic] gelungen, die Ursache und Wirkung der klassischen Musik in überzeugender Weise darzulegen « (Hartmann 1952, 52 und 48; Hervorhebung original).

165 Nach der Überzeugung Wingerts schafft Schenker das »Bewußtsein eines inneren Gleichgewichtes [...], eines Eingebettetseins in eine göttliche Ordnung, das uns vor seelischer Verarmung, vor Gehetztsein und vor einer Wiederholung wahnwitziger Katastrophen bewahren könnte« (Wingert 1950, 244; Hinweis und Zitat nach Schwab-Felisch 2005b, 244).

166 Für eine Gegenüberstellung der freilich sehr unterschiedlichen Herangehensweisen Hartmanns und Wingerts vgl. Schwab-Felisch 2005b, 243-245.

167 Koslovsky 2014, 152.

168 Freilich spielen auch bei Schenker Konzepte von und Begrifflichkeiten rund um >Tonalität eine große Rolle, wobei er diese wohl am eindrücklichsten 1914 in einem Gleichnis in seinem Tagebuch festhält: »Nur soll es [das Leben] auf einen Effekt hinauslaufen, der - um eine Analogie zu zitieren - vergleichbar wäre mit tonikalisierten ferneren Stufen einer Tonart; d.h. es ist z.B. nichts dagegen einzuwenden, wenn in Cdur die VI. oder VII. Stufe in den Tonikalisierungs-Zustand gerät u. hiebei die nötigen Chromen annimmt, die die Wirkung von selbständigen Stufen verleihen, ohne daß darüber aber das Zentrum der Tonika seiner Herrschaft verlustig gehen müßte. [...] Die Tonalität des Lebens wird durch eine falsche Anwendung der Chromen um die Tonika gebracht, Gelderwerb, Wohnung u. andere äußere Kultur werden wirklich zu Selbstzweck, also zu eigenen Tonarten. Vor lauter Tonarten verliert dann aber das Leben den eigenen großen tonal-zusammenfassenden Sinn. (Tagebucheintrag vom 6. November 1914; vgl. Schenker Documents Online, http://www.schenkerdocumentsonline.org/documents/diaries/OJ-0116_1914-11/r0006.html [30.6.2018]). 
zeigt, vor allem durch die Exilanten Jonas ${ }^{169}$ und Salzer sowie Adele Katz in den ersten Jahrzehnten nach Schenkers Tod geprägt: »In fact, he [Schenker] placed only a mild emphasis on the word stonality in his writings, preferring instead to develop and promote his own terminology. « ${ }^{170}$

In seinem Aufsatz gibt Federhofer stattdessen eine knappe Einführung in die wichtigsten Elemente der Theorien Schenkers. Einerseits überblickt er das notwendige methodische wie begriffliche Rüstzeug (das Hartmann in seinem Aufsatz offenbar als weitgehend

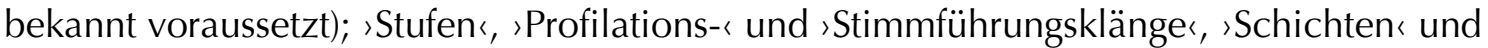

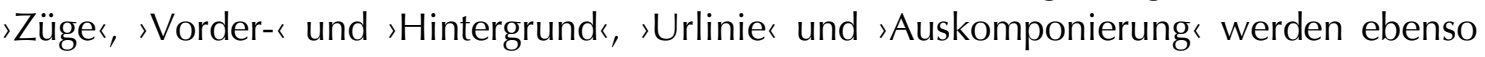
erläutert wie der Begriff der >Verlaufsgestaltı, welcher den Ausführungen zu Schenker wie bereits in der Habilitationsschrift - als Brücke zur Gestaltpsychologie vorangestellt wird. Andererseits kommen im Verlauf des Textes mit der Harmonielehre, dem Kontrapunkt, dem Freien Satz, den Reihen Der Tonwille und Das Meisterwerk in der Musik sowie den Fünf Urlinie-Tafeln auch die zentralen Schriften Schenkers zur Sprache. Dadurch lieferte Federhofer der deutschsprachigen Nachkriegsmusikwissenschaft und -theorie eine historische, theoretische wie auch bibliographische Arbeitsgrundlage, die darauf zielte, die Theorien Schenkers aus dem wissenschaftlichen Untergrund hervorzuholen und wieder zu einem gewichtigen Objekt des Fachdiskurses zu machen. Diese Absicht wird nicht zuletzt darin spürbar, dass auf jede Form der Polemik, ja selbst sachlicher Kritik weitestgehend verzichtet wird. Es fällt kein Wort mehr zu Kurths »z.T. völlig unzutreffenden analytischen Feststellungen ${ }^{171}{ }^{1}$, wie er sie in seiner Habilitationsschrift diagnostizierte, sondern es wird festgestellt, dass das, »[w]as Schenker indessen von Kurth, mit dem er denselben Standpunkt teilt, trennt, die Art und Weise [ist], wie die Verlaufsgestalt untersucht wird. « ${ }^{172}$ Auch Riemann, den bereits Schenker seit seiner Harmonielehre wiederholt zur Zielscheibe erklärt hatte ${ }^{173}$ und auf dessen Theorien Federhofer sich in seiner Habilitationsschrift (oft indirekt über den Umweg des Riemann-Schülers Hermann Erpf) kritisch bezieht, wird gleichberechtigt neben Schenker gestellt:

Die Dur-Moll-Tonalität bedeutet für Schenker wie für Riemann ein nach Durchlaufen vieler primitiver Vorstufen erreichtes Endziel der gesamten musikalischen Entwicklung. Wenn wir auch heute diese häufig zu unfruchtbarer Polemik führende Geschichtsauffassung, die im romantischen Fortschrittglauben wurzelt, ablehnen, so bleibt doch der Wert der Schenkerschen Theorie als deskriptive Musiktheorie des Dur-Moll-Zeitalters hievon [sic] unberührt. ${ }^{174}$

Bemerkenswert ist hier auch die Ablehnung jenes Konzepts, das die Dur-Moll-Tonalität als Höhe- und Endpunkt der europäischen Musikgeschichte begreift, wie es Federhofer

169 Jonas tendierte schon früher in diese Richtung, wie etwa sein Aufsatz Zum Begriff der Tonalität verdeutlicht, der 1932 in der Allgemeinen Musikzeitung erschien (Jonas 1932).

170 Koslovsky 2014, 152.

171 Federhofer 1943, 27, Anm. 1. Dass Federhofer mit seiner Kritik an Kurth einer der damals herrschenden Ideologie geschuldeten Erwartungshaltung entsprochen habe, ist unwahrscheinlich, da er den Wortlaut in den Beiträgen zur musikalischen Gestaltanalyse (Federhofer 1950, 29) nicht veränderte.

172 Federhofer 1947/2013, 2.

173 Vgl. Schenker 1906, VIIf. Wie Thomas Christensen (1982, 37) erläuterte, zielten Schenkers Angriffe allerdings vor allem auf Rameau, während Riemann eher beiläufig in die Kritik an der durch Rameau begründeten »fundamental bass school« miteingeschlossen wird.

174 Federhofer 1947/2013, 2, Anm. 2. 
später wieder selbst vertrat und das bereits in Musikalische Form als Ganzheit durchgeklungen war. ${ }^{175}$ Insgesamt ist Federhofers Bemühen allgegenwärtig, seinen Text von den problematischen Komponenten der Schenker'schen Sprache freizuhalten.

Mit den Beiträgen zur musikalischen Gestaltanalyse lieferte Federhofer drei Jahre später schließlich eine Sammlung an Texten, die Schenkers Theorien umfassend darstellen. Die einzelnen Beiträge waren nach eigener Aussage bereits zwischen 1943 und 1946, also im Anschluss an die Habilitationsschrift entstanden, konnten aber »infolge der Nachkriegsverhältnisse « ${ }^{176}$ erst 1950 veröffentlicht werden. Zusammen mit einer Wiederveröffentlichung seiner Habilitationsschrift Musikalische Form als Ganzheit als drittem Kapitel (das ein britischer Rezensent als »most considerable paper ${ }^{177}$ der Sammlung bezeichnete) liefern die ersten zwei Kapitel »Reduktionstechnik und Gestaltanalyse« sowie »Klangfunktionen der Dur-Moll-Harmonik« eine umfassende Hin- und Einführung zu Schenkers Theorienkomplex (inklusive einer veritablen Riemann-Kritik im zweiten Kapitel) ${ }^{178}$, während das Kapitel »Der strenge und freie Satz und sein Verhältnis zur Kompositionslehre von Heinrich Schütz in der Fassung seines Schülers Christoph Bernhard « wesentliche Prinzipien der Theorien Schenkers an frühbarocker Musik aufzeigt, ohne diese nach der Schichtenlehre zu analysieren. ${ }^{179}$ An den Beginn des Kapitels »Tonale und reale Beantwortung bei J.S. Bach« stellt Federhofer schließlich die Kritik, dass gängige Theorien auch die Gattung Fuge lediglich als summatives Ereignis behandelten: „Um den Formverlauf in seiner ganzheitlichen Erscheinung zu analysieren, genügt nicht der bloße Aufweis des Wechsels von Thema und Nichtthema, sondern es muß jenes Formungsprinzip aufgedeckt werden, das diese Einheitlichkeit gewährleistet. " ${ }^{180}$ Die anschließende Untersuchung basiert wieder vor allem auf Schenkers Theorien. Die teils starke Polemik gegen andere Theoretiker und deren Konzepte, die den gemeinsamen Entstehungskontext mit der Habilitationsschrift deutlich macht, unterstreicht dabei zusätzlich, wie sehr Federhofer in "Die Musiktheorie Heinrich Schenkers « um eine neutrale und versöhnliche Position bemüht war. Federhofers Beiträge fanden durchaus weite Verbreitung und wurden nicht nur in Deutschland ${ }^{181}$, sondern auch in Großbritannien ${ }^{182}$ und Nordamerika ${ }^{183}$ rezensiert.

175 »Zweifellos liegt hierin [in der zwingenden Kraft des Dreiklangs] ein großer Vorzug der DurMolltonalität anderen Musiksystemen gegenüber und die Möglichkeit, Einheiten größten Ausmaßes auf ihrer Grundlage erstehen zu lassen« (Federhofer 1943, 37, Fußnote).

176 Federhofer 1950, 1, Anm. 1.

177 Capell 1951, 179.

178 Tatsächlich hat Federhofer vor allem in späteren Jahren stärker als andere Theoretiker die Kluft zwischen Schenker und Riemann betont (vgl. Christensen 1982, 37).

179 Vor allem geht es Federhofer in diesem Kapitel um den Nachweis, dass bereits Bernhard die innere Einheit von strengem und freiem Satz, wie sie auch Schenker postulierte, bewusst war. Diese Wechselwirkung von stylus antiquus und stylus modernus, die »nicht feindlich einander gegenüber [traten], sondern [...] als Ausprägung unterschiedlicher, satztechnisch jedoch aufeinander bezogener Stilarten verstanden [wurden] « (Federhofer 1997/2002, 291), diente Federhofer dabei wiederholt als Argument für den "grundlegende[n] Wandel«, den die neue Musik im 20. Jahrhundert heraufbeschworen habe: »Die Bestimmungsmerkmale des Neuen veränderten sich in einem derartigen Ausmaß, daß ein gemeinsamer Nenner zwischen alt und neu, der den Verlauf traditioneller Musik bestimmte, nicht mehr ersichtlich wurde. Anstelle eines fließenden Übergangs, dem die Musik bisher folgte, was eine Anpassung an das Neue ermöglichte, trat ein Bruch.« (Federhofer 1999/2002, 382)

180 Federhofer 1950, 79.

181 Vgl. Mies 1952.

182 Vgl. Capell 1951. 
Dabei spiegelt sich in den Rezensionen der damalige Stand der internationalen SchenkerRezeption: Richard Capell stellt aus seiner britischen Perspektive fest, dass »[w]e in England have so far shown little interest in this abstruse yet fascinating and penetrating method of musical analysis. Apart from Central Europe, only in the U.S.A., thanks largely to his Austrian disciples settled there, is Schenker now seriously studied « ${ }^{184}$. Dementsprechend wendet Capell den Großteil des Textes dafür auf, den Leser*innen Schenkers Konzepte näher zu bringen, anstatt Federhofers Arbeit tatsächlich zu beurteilen. Demgegenüber setzt Paul Mies in seiner Rezension die wesentlichen Prinzipien der Theorien als bekannt voraus und bringt auch ausgewählte Kritikpunkte an. Erwähnenswert ist ferner, dass immerhin aus einer britischen, das heißt: nicht-deutschen Perspektive Federhofers Darstellungsweise als "cool, clear-headed and scientific « ${ }^{185}$ charakterisiert und damit offenbar als von einem damals mit Schenker in Verbindung gebrachten Stil abweichend wahrgenommen wird.

\section{FAZIT}

Ziel der vorangegangenen Ausführungen war es, die frühe Schenker-Rezeption Hellmut Federhofers vor dem Hintergrund seiner musikalischen Ausbildung und seines beruflichen Werdegangs zu durchleuchten. Dabei wurde deutlich, dass Federhofer, angeregt durch den Kontakt zum Wiener Schenker-Kreis, dessen Theorien nicht nur über Jahre hinweg intensiv studierte, sondern sie sogar seiner 1943 vorgelegten Habilitationsschrift zugrunde legte. Dass Federhofers Arbeit, die ohne eine Verschleierung der Schenker'schen Methoden und Terminologie auskommt, unter den damaligen politischen Umständen möglich war, legt die bewusste Zustimmung mindestens seines Betreuers Werner Danckert nahe, wobei die genauen Umstände dieses Vorgangs aus der momentanen Quellenlage nicht näher rekonstruierbar sind. Als Federhofer nach dem Ende des Zweiten Weltkriegs die Leitung des Musikwissenschaftlichen Instituts der Karl-Franzens-Universität Graz übernahm, machte er Schenker zu einem zentralen Gegenstand sowohl seiner Lehre als auch seiner ersten Publikationen und wurde so zu einem Vorreiter der europäischen Schenker-Rezeption nach 1945. In seinen frühen Schriften bleibt Federhofer dabei methodisch wie begrifflich eng den Arbeiten Schenkers verhaftet, erweitert sie jedoch in Hinblick auf die Formwahrnehmung um grundsätzliche Aspekte der Gestalttheorie. Mit Friedrich Neumanns 1958 vorgelegter Arbeit Der Typus des Stufenganges der Mozart'schen Sonatendurchführung dürfte Federhofer zudem die erste Dissertation zu Heinrich Schenker im deutschsprachigen Raum nach dem Ende des Zweiten Weltkriegs angeregt haben. Obgleich es sich bei Federhofer in Anbetracht seines weiteren Werdegangs zweifellos um eine außergewöhnliche Erscheinung innerhalb der europäischen SchenkerRezeption handelt, so darf mit Blick auf die Umstände seines Habilitationsprozesses mit vorsichtigem Optimismus vermutet werden, dass auch an anderen deutschen und österreichischen Institutionen während der NS-Zeit inkriminierte Theoretiker wie Schenker unter ähnlichen Bedingungen rezipiert worden sein könnten - das Desiderat an entsprechenden Lokalstudien ist jedenfalls gegeben. 


\section{Literatur}

Bamberger, Carl (1936), „Das Schenker-Institut am Neuen Wiener Konservatorium «, Anbruch 18/1, 7-8.

Berry, David C. (2004), A Topical Guide to Schenkerian Literature: An Annotated Bibliography with Indices, Hillsdale (NY): Pendragon.

Blume, Friedrich (1999), »Birtner, Herbert« [1949], in: Die Musik in Geschichte und Gegenwart Online, hg. von Laurenz Lütteken, Kassel: Bärenreiter / Stuttgart: Metzler / New York: RILM, online veröffentlicht 2016. https://www.mgg-online.com/mgg/stable/19617 (30.6.2018)

Capell, Richard (1951), „Beiträge zur Musikalischen Gestaltanalyse« [Rezension], Music and Letters 32/2, 177-180.

Christensen, T[h]om[as] (1982), »The Schichtenlehre of Hugo Riemann«, In Theory Only 6/4, 37-44.

Cook, Nicholas (2007), The Schenker Project: Culture, Race, and Music Theory in Fin-desiècle Vienna, New York: Oxford University Press.

Cube, Felix-Eberhard von (1988), The Book of the Musical Artwork. An Interpretation of the Musical Theories of Heinrich Schenker, übersetzt und hg. von David Neumeyer, George R. Boyd und Scott Harris: Lewiston (NY): Edwin Mellen Press.

Dahlhaus, Carl (1971), »Ist die Zwölftontechnik sillusorisch`? Eine Erwiderung«, Musikforschung 24/4, 437-440.

Dahlhaus, Carl (1983), »Im Namen Schenkers«, Die Musikforschung 36/2, 82-87.

Danckert, Werner (1934), Beiträge zur Bachkritik I, Kassel: Bärenreiter.

Drabkin, William (1986), »Felix-Eberhard von Cube and the North-German Tradition of Schenkerism«, Proceedings of the Royal Musical Association 111, 180-207.

Drabkin, William (2002), »Heinrich Schenker", in: The Cambridge History of Western Music Theory, hg. von Thomas Christensen, Cambridge: Cambridge University Press, 812-843.

Eggebrecht, Hans Heinrich (2001), „Federhofer, Hellmut«, in: Grove Music Online, New York: Oxford University Press. https://doi.org/10.1093/gmo/9781561592630.article.09408 (30.6.2018)

Ehrenfels, Christian von (1890), »Ueber `Gestaltqualitäten« «, Vierteljahrsschrift für wissenschaftliche Philosophie 14/3, 249-292.

Federhofer, Hellmut (1936), Akkordik und Harmonik in frühen Motetten der Trienter Kodices, Phil. Diss., Karl-Franzens-Universität Graz.

Federhofer, Hellmut (1943), Musikalische Form als Ganzheit, Habil., Karl-FranzensUniversität Graz.

Federhofer, Hellmut (1947/2013), „Die Musiktheorie Heinrich Schenkers«, in: ders., Theorie als Brücke zur Praxis. Gesammelte musiktheoretische Aufsätze, hg. von Josef Karner, Hildesheim: Olms, 1-5.

Federhofer, Hellmut (1950), Beiträge zur musikalischen Gestaltanalyse, Graz: Akademische Druck- und Verlagsanstalt. 
Federhofer, Hellmut (1950/2013): »Der strenge und freie Satz und sein Verhältnis zur Kompositionslehre von Heinrich Schütz in der Fassung seines Schülers Christoph Bernhard", in: ders., Theorie als Brücke zur Praxis. Gesammelte musiktheoretische Aufsätze, hg. von Josef Karner, Hildesheim: Olms, 6-29.

Federhofer, Hellmut (Hg.) (1960), Festschrift Alfred Orel zum 70. Geburtstag, Wien: Rohrer.

Federhofer, Hellmut (1963), „Die Diminution in Klavierwerken von Chopin und Liszt«: Bericht über die Zweite Internationale Musikwissenschaftliche Konferenz Liszt Bartók, Budapest 1961, Studia musicologica Academiae Scientiarum Hungaricae 5/14 (1963), 49-57.

Federhofer, Hellmut (1964a), „Gegen eine Schmähung der deutschsprachigen Musikwissenschaft", Musikerziehung 17/5, 215-219.

Federhofer, Hellmut (1964b), »Antwort auf den offenen Brief von DDr. Harald Kaufmann, Graz«, Musikerziehung 18/2, 74-75.

Federhofer, Hellmut (1966), „Trienter Kodices«, in: Die Musik in Geschichte und Gegenwart. Allgemeine Enzyklopädie der Musik, 1. Auflage, hg. von Friedrich Blume, Bd. 13, Kassel: Bärenreiter, 666-673.

Federhofer, Hellmut (1967), »Alfred Orel zum Gedächtnis«, Die Musikforschung 20/4, 363-364.

Federhofer, Hellmut (1981), Akkord und Stimmführung in den musiktheoretischen Systemen von Hugo Riemann, Ernst Kurth und Heinrich Schenker, Wien: Österreichische Akademie der Wissenschaften.

Federhofer, Hellmut (1982/2002), »Meine Erinnerungen an Alban Berg«, in: ders., Neue Musik als Widerspruch zur Tradition. Gesammelte Aufsätze (1968-2000), Bonn: Orpheus, 94-99.

Federhofer, Hellmut (1984), »Im Namen Schenkers. Eine Erwiderung«, Die Musikforschung 37/1, 21-24.

Federhofer, Hellmut (1985) (Hg.), Heinrich Schenker. Nach Tagebüchern und Briefen in der Oswald Jonas Memorial Collection, University of California, Riverside, Hildesheim: Olms.

Federhofer, Hellmut (1990) (Hg.), Heinrich Schenker als Essayist und Kritiker. Gesammelte Aufsätze, Rezensionen und kleinere Berichte aus den Jahren 1891-1901, Hildesheim: Olms.

Federhofer, Hellmut (1997/2002), »ohannes Brahms zwischen Tradition und Fortschritt", in: ders., Neue Musik als Widerspruch zur Tradition. Gesammelte Aufsätze (19682000), Bonn: Orpheus, 291-301.

Federhofer, Hellmut (1999/2002), „Neue Musik und moderne Demokratie«, in: ders., Neue Musik als Widerspruch zur Tradition. Gesammelte Aufsätze (1968-2000), Bonn: Orpheus, 382-392.

Federhofer, Hellmut (2000/2002), „Der Freiheitsbegriff in der `Neuen Musikı«, in: ders., Neue Musik als Widerspruch zur Tradition. Gesammelte Aufsätze (1968-2000), Bonn: Orpheus, 433-443. 
Federhofer, Hellmut (2015), Die Musik hat das letzte Wort. Eine Nachrede zum 200. Geburtstag von Richard Wagner, in: Fluchtpunkt Italien. Festschrift für Peter Ackermann, hg. von Johannes V. Schmidt und Ralf-Olivier Schwarz, Hildesheim: Olms, 355-358.

Federhofer, Hellmut (2016), »Federhofer, Hellmut« [2001], in: Die Musik in Geschichte und Gegenwart Online, hg. von Laurenz Lütteken, Kassel: Bärenreiter/Stuttgart: Metzler / New York: RILM, online veröffentlicht 2016. https://www.mgg-online.com/mgg/stable/28730 (30.6.2018)

Federhofer, Hellmut / Albert Wellek (1971), »Tonale und dodekaphonische Musik im experimentellen Vergleich", Musikforschung 24/3, 260-276.

Flotzinger, Rudolf (1990), 50 Jahre Institut für Musikwissenschaft, Graz: Institut für Musikwissenschaft der Karl-Franzens-Universität.

Fox, Charles Warren (1951), „Beitraege zur musikalischen Gestaltanalyse« [Rezension], Notes 8/4, 714.

Gruber, Gernot (2013), „Zum Geleit«, in: Hellmut Federhofer; Theorie als Brücke zur Praxis. Gesammelte musiktheoretische Aufsätze, hg. von Josef Karner, Hildesheim: Olms, VIII-X.

Haken, Boris von (2017), »Fellerer, Karl Gustav«, in: Die Musik in Geschichte und Gegenwart Online, hg. von Laurenz Lütteken, Kassel: Bärenreiter / Stuttgart: Metzler / New York: RILM. https://www-1 mgg-2online-1 com-1000046tn0170.han.kug.ac.at/mgg/stable/13662 (30.6.2018)

Harten, Uwe (2001), "Salzer, Felix«, in: Österreichisches Musiklexikon Online, Wien: Österreichische Akademie der Wissenschaften. http://www.musiklexikon.ac.at/ml/ musik_S/Salzer_Felix.xml (30.6.2018)

Hartmann, Heinrich (1952), „Heinrich Schenker und Karl Marx«, Österreichische Musikzeitschrift 7, 46-52.

Heller, Lynne (2017), »`Nun bin ich Musiker mit Ernst und ohne Reue««, mdw-Webmagazin 2018/1. https://www.mdw.ac.at/magazin/index.php/2017/12/01/nun-bin-ich-musiker-miternst-und-ohne-reue/ (30.6.2018)

Hilscher, Elisabeth Th. (2001), „Federhofer, Hellmut", in: Österreichisches Musiklexikon Online, Wien: Österreichische Akademie der Wissenschaften. http://www.musiklexikon. ac.at/ml/musik_F/Federhofer_Hellmut.xml (30.6.2018)

Holtmeier, Ludwig (2003), „Von der Musiktheorie zum Tonsatz. Zur Geschichte eines geschichtslosen Faches", ZGMTH 1/1 (2003), 11-34, https://www.gmth.de/zeitschrift/ artikel/481.aspx (30.6.2018)

Hornbostel, Erich von (1930), „Gestaltpsychologisches zur Stilkritik«, in: Studien zur Musikgeschichte. Festschrift für Guido Adler zum 75. Geburtstag, o.H., Wien: UniversalEdition, 12-16.

Jonas, Oswald (1932), »Zum Begriff der Tonalität«, Allgemeine Musikzeitung 59/18 (6. Mai), 245-246.

Jonas, Oswald (1933), »Heinrich Schenker«, Allgemeine Musikzeitung 60/36 (8. September), 425-427, und 60/37 [15. September], 437-439. 
Kaufmann, Harald (1969a), »Fortschritt und Reaktion in der Analysenlehre Heinrich Schenkers", in: ders., Spurlinien. Analytische Aufsätze über Sprache und Musik, Wien: Lafite, 37-46.

Kaufmann, Harald (1969b), »Aushöhlung der Tonalität bei Reger«, in: ders., Spurlinien. Analytische Aufsätze über Sprache und Musik, Wien: Lafite, 175-189.

Koslovsky, John (2014), »The early Schenkerians and the ‘Concept of Tonality«", Gamut 7/1, 151-185.

Kurth, Ernst (1917), Grundlagen des Linearen Kontrapunkts. Einführung in Stil und Technik von Bach's melodischer Polyphonie, Bern: Drechsel.

Laaff, Ernst / Albert Wellek (1951), "Atonalität", in: Die Musik in Geschichte und Gegenwart. Allgemeine Enzyklopädie der Musik, 1. Auflage, hg. von Friedrich Blume, Bd. 1, Kassel: Bärenreiter, 760-766.

László, Alexander (2006), „Die Farblichtmusik und ihre Forschungsgebiete. Ein Vortrag für Universitäten, Colleges und musikalische Hochschulen« [gehalten Dezember 1939], in: Farbe - Licht - Musik. Synästhesie und Farblichtmusik, hg. von Jörg Jewanski und Natalia Sidler, Bern: Lang, 276-337.

Lederer, Josef-Horst (2014), »Univ.-Prof. Dr. Dr. hc. Hellmut Federhofer (1911-2014)« [Nachruf], Musicologica Austriaca 31, 259-261.

Mahling, Christoph-Hellmut (Hg.) (1988), Florilegium Musicologicum. Hellmut Federhofer zum 75. Geburtstag, Tutzing: Schneider.

Mann, Michael (1949), "Schenker's Contribution to Music Theory", The Music Review 10/1, 2-26.

Martin, Bernhard (1941), Untersuchungen zur Struktur der "Kunst der Fuge" J.S. Bachs, Regensburg: Bosse.

Marx, Joseph (1935), „Der Musikforscher Heinrich Schenker«, Neues Wiener Journal 43/14801 (3. Februar), 8.

Mies, Paul (1952), »Hellmut Federhofer: Beiträge zur musikalischen Gestaltanalyse« [Rezension], Musikforschung 5/1, 71-72.

Neumann, Friedrich (1951), Synthetische Harmonielehre, Leipzig: Breitkopf \& Härtel.

Neumann, Friedrich (1955), Tonalität und Atonalität. Versuch einer Klärung, Landsberg a.L.: Hohler.

Orel, Alfred (1977), Die Hauptstimme in den "Salve regina" der Trienter Codices [Phil. Diss., Universität Wien 1919], Tutzing: Schneider.

Orel, Alfred (1922), Über rhythmische Qualität in mehrstimmigen Tonsätzen aus dem 15. Jh., Habil., Universität Wien.

Orel, Alfred (1941), »Mozarts deutscher Weg", Die Pause 6/12, 14-17 und 37.

Orel, Alfred (1954), „Die Wende zur `Neuen Musikı im historischen Aspekt«, Schweizerische Musikzeitung 94/1, 1-9.

Ortner, Oswald (Hg.) (1947), Joseph Marx. Betrachtungen eines romantischen Realisten, Wien: Gerlach \& Wiedling.

Plum, Karl-Otto (1984), »Zu Carl Dahlhaus' Beitrag `Im Namen Schenkers««, Die Musikforschung 37/1, 24-26. 
Potter, Pamela (2000), Die deutscheste der Künste. Musikwissenschaft und Gesellschaft von der Weimarer Republik bis zum Ende des Dritten Reichs, übersetzt von Wolfram Ette, Stuttgart: Klett-Cotta.

Reich, Willi (1963), Alban Berg. Leben und Werk, Zürich: Atlantis.

Riedel, Friedrich W. / Hubert Unverricht (Hg.) (1971), Symbolae Historiae Musicae. Hellmut Federhofer zum 60. Geburtstag überreicht von Freunden, Kollegen und Schülern, Mainz: Schott.

Salzer, Felix (1935), Sinn und Wesen der abendländischen Mehrstimmigkeit, Wien: Saturn.

Salzer, Felix (1937), »Die historische Sendung Heinrich Schenkers«, Der Dreiklang. Monatsschrift für Musik 1, 2-12.

Salzer, Felix (1952), Structural Hearing: Tonal Coherence in Music (2 Bde.), New York: Boni.

Salzburger Chronik für Stadt und Land (1936), 72/198 (29. August).

Salzburger Volksblatt (1936), 66/1 (29. August).

Schäfke, Rudolf (1982), Geschichte der Musikästhetik in Umrissen [1934], 3. Auflage, Tutzing: Schneider.

Schenker, Heinrich (1895), „Der Geist der musikalischen Technik«, Musikalisches Wochenblatt 26/19-26, 245-246, 257-259, 273-274, 285-286, 297-298, 309-310, 325-326.

Schenker, Heinrich (1906), Harmonielehre (= Neue musikalische Theorien und Phantasien, Bd. 1), o.O.: o.V.

Schenker, Heinrich (1971), Beethoven. Die letzten Sonaten: Sonate E-Dur op. 109. Kritische Einführung und Erläuterung [1913], neu hg. von Oswald Jonas, Wien: Universal Edition.

Schenker, Heinrich (1922a), »Beethoven: V. Sinfonie«, Der Tonwille 1, 27-37.

Schenker, Heinrich (1922b), »Gesetze der Tonkunst«, Der Tonwille 2, 3.

Schenker, Heinrich (1922c), »Mozart: Sonate A-Moll (Köchel-Verzeichnis Nr. 310) «, Der Tonwille 2, 7-24.

Schenker, Heinrich (1925), »Joh. S. Bach. Sechs Sonaten für Violine. Partita III (E-Dur) Präludio«, in: ders., Das Meisterwerk in der Musik, Bd. 1, München: Drei Masken, 75-98.

Schenker, Heinrich (1926), „Ein Gegenbeispiel: Max Reger, op. 81, Variationen und Fuge über ein Thema von Joh. Seb. Bach für Klavier«, in: ders., Das Meisterwerk in der Musik, Bd. 2, München: Drei Masken, 171-192.

Schenker, Heinrich (1954), Harmony, übersetzt von Elisabeth Mann Borgese, hg. von Oswald Jonas, Chicago: Chicago University Press.

Schenker, Heinrich (1956), Der freie Satz (= Neue musikalische Theorien und Phantasien, Bd. 3) [1935], 2. bearbeitete Auflage, hg. von Oswald Jonas, Wien: Universal Edition.

Schenker, Heinrich (2000), The Art of Performance [1911], übersetzt von Irene Schreier Scott, hg. von Heribert Esser, New York: Oxford University Press.

Schenker Documents Online, »Ernst Oster«. http://www.schenkerdocumentsonline.org/ profiles/person/entity-000649.html (30.6.2018)

Schenker Documents Online, »Hans Weisse«. http://www.schenkerdocumentsonline.org/ profiles/person/entity-000951.html (30.6.2018) 
Schenker Documents Online, »Manfred (Herrand Joseph) Willfort« http://www.schenker documentsonline.org/profiles/person/entity-000964.html (30.6.2018)

Schenker Documents Online, »Oswald Kabasta«. http://www.schenkerdocumentsonline.org/ profiles/person/entity-003836.html (30.6.2018)

Schenker Documents Online, FS 40/1, [17] (24. September 1933), transkribiert und übersetzt von Hedi Siegel (2011). http://www.schenkerdocumentsonline.org/documents/ correspondence/FS-40-1_17.html (30.6.2018)

Schenker Documents Online, WSLB 418/1 (19. Dezember 1929), transkribiert und übersetzt von Ian Bent (2012). http://www.schenkerdocumentsonline.org/documents/ correspondence/WSLB-418-1.html (30.6.2018)

Schenker Documents Online, »Diary entry by Schenker November 6, 1914«, transkribiert von Marko Deisinger, übersetzt von William Drabkin. http://www.schenker documentsonline.org/documents/diaries/OJ-01-16_1914-11/r0006.html (30.6.2018)

Schenker Documents Online, „Diary entry by Schenker June, 1931 «, transkribiert von Marko Deisinger, übersetzt von William Drabkin. http://www.schenkerdocumentsonline.org/ documents/diaries/OJ-04-04_1931-06/r0019.html (30.6.2018)

Schenker Documents Online, „Diary entry by Schenker July, 1931 «, transkribiert von Marko Deisinger, übersetzt von William Drabkin. http://www.schenkerdocumentsonline.org/ documents/diaries/OJ-04-04_1931-07/r0027.html (30.6.2018)

Schenker Documents Online, » Diary entry by Schenker December, 1931 «, transkribiert von Marko Deisinger, übersetzt von William Drabkin. http://www.schenkerdocumentsonline. org/documents/diaries/OJ-04-05_1931-12/r0007.html (30.6.2018)

Schwab-Felisch, Oliver (2005a), „Zur Schichtenlehre Heinrich Schenkers", in: Musiktheorie (= Handbuch der systematischen Musikwissenschaft, Bd. 2), hg. von Helga de la Motte-Haber und Oliver Schwab-Felisch, Laaber: Laaber, 337-376.

Schwab-Felisch (2005b), „Zur Rezeption der Schichtenlehre Heinrich Schenkers in der deutschsprachigen Musikwissenschaft nach 1945", ZGMTH 2/2-3, 243-247. https://storage.gmth.de/zgmth/pdf/532 (30.6.2018)

Skorzeny, Fritz / Karl Daumer / Roland Tenschert (1941), »Aus dem Musikleben«, Neues Wiener Tagblatt 75/298 (27. Oktober), 5.

Slottow, Stephen (2008), „Schenkerian Pedagogy in the Salzer and Oster Teaching Lines: An Oral History Approach", in: Essays from the Fourth International Schenker Symposium, Bd. 1, hg. von Allen Cadwallader, Hildesheim: Olms, 259-278.

Staudinger, Michael (2006), » Finstere Dämonen`. Zur Geschichte der Musikwissenschaft an der Universität Wien in den Jahren 1938-1945«, in: Musik in Wien 1938-1945, hg. von Carmen Ottner, Wien: Doblinger, 239-255.

Stöhr, Richard (1933), Formenlehre der Musik, unter Mitarbeit von Hans Gál und Alfred Orel, Leipzig: Kistner \& Siegel.

Suppan, Wolfgang (1971), »Werner Danckert, 1900-1970«, Ethnomusicology 15/1, 94-99.

Suppan, Wolfgang (1997), » Musik der Menge`. `Volkı und `Volksmusikı in den Schriften Heinrich Schenkers und seines Schülers Viktor Zuckerkandl«, in: Festschrift Walter Wiora zum 90. Geburtstag, hg. von Christoph-Hellmut Mahling und Ruth Seiberts, Tutzing: Schneider, 471-491. 
Suppan, Wolfgang (2002), „Geleitwort«, in: ders., Neue Musik als Widerspruch zur Tradition. Gesammelte Aufsätze (1968-2000), Bonn: Orpheus, 3-5.

Suppan, Wolfgang (2009), »Federhofer Hellmut«, in: Steirisches Musiklexikon, 2. Auflage, hg. von Wolfgang Suppan, Graz: Akademische Drucks- und Verlagsanstalt, 132-140.

Tan, Daphne (2015), »Beyond Energetics: Gestalt Psychology in Ernst Kurth's Musikpsychologie", Theoria. Historical aspects of music theory 22, 99-130.

Universität für Musik und darstellende Kunst Wien [o.J.], »Analyse nach Heinrich Schenker. Franz Eibner«. http://www.mdw.ac.at/schenkerlehrgang/franz_eibner.html (30.6.2018)

Utz, Christian (2016), »Räumliche Vorstellungen als `Grundfunktionen des Hörens`. Historische Dimensionen und formanalytische Potenziale musikbezogener Architekturund Raummetaphern - eine Diskussion anhand von Werken Guillaume Dufays, Joseph Haydns und Edgard Varèses«, Acta Musicologica 88/2, 193-221.

Wagner, Günter (Hg.) (1996), » „Der Teufel selbst kann nicht merken, was echt und was falsch istı. Reflexionen über Neue Musik - Hans Gál im Briefwechsel mit Hellmut Federhofer", Mitteilungen der Arbeitsgemeinschaft für mittelrheinische Musikgeschichte $66,1-49$.

Wellek, Albert (1971), „Grußwort Hellmut Federhofer zum 60. Geburtstag«, in: Symbolae Historiae Musicae. Hellmut Federhofer zum 60. Geburtstag überreicht von Freunden, Kollegen und Schülern, hg. von Friedrich W. Riedel und Hubert Unverricht, Mainz: Schott, 7-9.

Westphal, Kurt (1935), Der Begriff der musikalischen Form in der Wiener Klassik. Versuch einer Grundlegung der Theorie der musikalischen Formung, Leipzig: Kistner \& Siegel.

Wingert, Hans (1950), „Über die „Urlinie` und ihren Schöpfer", Zeitschrift für Musik $111 / 5,244-246$.

Wörner, Felix (2008), „Der Einfluss der Gestalttheorie auf die deutsche FormenlehreTradition im ersten Drittel des 20. Jahrhunderts", in: Musiktheorie im Kontext. 5. Kongress der Gesellschaft für Musiktheorie Hamburg 2005, hg. von Jan Philipp Sprick, Reinhard Bahr und Michael von Troschke, Berlin: Weidler, 403-415.

Wörner, Felix (2014), „Zur Konzeption smusikalisches Hören` in der Musiktheorie von Ernst Kurth«, in: Gestalt und Gestaltung in interdisziplinärer Perspektive, hg. von Ellen Aschermann und Margret Kaiser-el-Safti, Frankfurt a.M.: Lang, 205-217.

Wozonig, Thomas (2018): Die frühe Schenker-Rezeption Hellmut Federhofers. ZGMTH 15/1, 121-158. https://doi.org/10.31751/967

(C) 2018 Thomas Wozonig (t.wozonig@kug.ac.at)

Dieser Text erscheint im Open Access und ist lizenziert unter einer

Creative Commons Namensnennung 4.0 International Lizenz.

This is an open access article licensed under a

(c)

Creative Commons Attribution 4.0 International License.

eingereicht / submitted: 12/03/2018

angenommen / accepted: 04/05/2018

veröffentlicht / first published: 30/06/2018

zuletzt geändert / last updated: 03/08/2018 